\title{
PERSPECTIVAS DE INTEGRACIÓN ENERGÉTICA MÉXICO-NORTEAMERICANA: INTERCAMBIOS DE ELECTRICIDAD Y GAS NATURAL EN EL NOROESTE MEXICANO
}

\author{
Por \\ Agustín Sández Ptrez* \\ A la memoria del Dr. Rafael Molina Berbeyer
}

\section{RESUMEN}

Históricamente, la relación comercial México-norteamericana en el plano energético ha sido hegemonizada por el intercambio de hidrocarburos. En épocas de conflagración mundial, y más recientemente de conflictos bélicos en el Medio Oriente, el acceso preferencial a este recurso ha representado un factor importante de tensión para México. Fuera de las etapas de tensión, tal intercambio continúa siendo eje de la negociación comercial y aún más lejos, ha llegado a ocupar en algunos periodos un rol clave en la planeación económica global de la nación.

Esta relación abrumadora, que parece privilegiar a toda costa el examen del intercambio petrolero en la relación comercial bilateral es, en cambio, ajena y distante al panorama social y productivo de la frontera norte y muy especialmente del noroeste mexicano. Enéste, el intercambio energéticose circunscribe hoy a la venta de electricidad hacia el norte y la venta de gas natural hacia el sur de la frontera entre ambos paises.

El surgimiento de los circuitos eléctricos interconectados entre Baja California y California es un proceso relativamente reciente. Hacia mediados de los ochenta se realizaron las negociaciones entre autcridades y representantes de ambos países. Esta negociación reflejó, a su vez, la disparidad onganizacional de la producción eléctrica.

Más recientemente se han establecido programas y políticas destinadas al uso eficiente de la energía. A la vez se presencian procesos paralelos de gran trascendencia. Una de las alternativas que se discuten hoy para el abatimiento de costos de producción es la utilización del gas natural como alimento de la termoelectricidad a fin de sostener la capacidad instalada y asegurar la exportación.

\section{ABSTRACT}

Historically, the Mexican-American commercial relationship in the energetic level has been consolidated by the exchange of petroleum. In times of world conflict and more recently war conflicts in the Middle East, the preferential access to this resource has played an important factor of tension towards Mexico. Out of the stage of tension, such exchange keeps on being the axle of the commercial negotiations and even farther, it has occupied in some periods of time a key role in the global economic planning of the nation.

- Investigador del Instituto de Investigaciones Sociales, UABC. Miembro de la Sociedad Mexicana de Ecología y Estadística (1990) y del Sistema Nacional de Investigadores 
This overwhelming reality, that seems to favor at all cost the examination of the oil exchange in the bilateral commercial relationship is, on the other hand, strange and distant to the social productive panoramic of the Northern border and specifically the Mexican Northwest. Here, the energetic exchange is circumscribed to the sale of electricity to the North and the sale of natural gas to the South of the border.

The emerge of electronic circuits interconnected within Baja California and Califomia is a relatively recent process. By the mid-eighties, negotiations were made between authorities and representatives of both countries. These negotiations reflected the organizational disparity of the electricity production.

More recently, programs and policies have been establishedin order to have an efficient use of energy. At the same time, parallel processes of great consequence have been witnessed. One of the alternatives discussed today to reduce the production cost is the usage of natural gas to feed the thermo-electricity to sustain the installed capacity and to insure the exportation.

\section{INTRODUCCIÓN ${ }^{1}$}

Este documento tiene como base un conjunto amplio de notas relacionadas con el desempefo reciente del sector energético mexicano en su necesaria concatenación con los mecanismos vigentes y condiciones de la negociación trilateral en marcha. Pretende ofrecer un horizonte válido para situar algunas ideas preliminares en el desarrollo de una investigación de mayor alcance en el tema. Por ello, más que un ensayo acabado, el texto se dirige a bosquejar algunos elementos relevantes en la búsqueda de hilos conductores para el actual proceso de integración energética en el marco del bloque norteamericano.

La primer sección, apunta en forma breve algunos rasgos del actual proceso de integración, destacando particularmente la heterogénea visión que sobre la cuestión energética corresponde a agentes y sectores en los países involucrados. En una segunda se incluyen aspectos del desempefio reciente del sector energético mexicano - con énfasis en el ramo eléctrico y gasero- dadas sus importantes repercusiones en el ámbito fronterizo. Finalmente, una tercera sección presenta algunos eventos que fundamentan el énfasis notable con que este proceso profundiza sus manifestaciones en el presente y futuro inmediato de la frontera norte de México.

1 Presentado en el Tercer Congreso Internacional sobre Fronteras en Iberoamérica, que tuvo lugar en la frontera colombo-venezolana, en noviembre de 1992. Se agradece el apoyo financiero brindado por CONACYT al programa de investigación a cargo del área de Energía, Frontera y Sociedad del Instituto de Investigaciones Sociales de la UABC, del cual el presente documento constituye un subproducto, en cuya elaboración destaca la participación de la socióloga Norma García Leos. 
El surgimiento de circuitos eléctricos interconectados y una mayor infraestructura transfronteriza para el comercio de gas natural constituyen un proceso que anticipa una profundización de las actividades asociadas al comercioenergético desde una óptica bilateral, y tal vez pronto, trilateral.

\section{LA CUESTIÓN ENERGÉTICA EN LA NEGOCIACIÓN TRILATERAL}

\section{Contexto de la regionalización económica norteamericana}

El escenario económico mundial de los noventa revela tendencias de una reestructuración capitalista que manifiesta nuevos mecanismos de competencia apoyados en una regionalización que comprende tres bloques principales: europeo, asiático y americano. En este sentido, durante décadas, se efectuaron importantes desplazamientos de la inversión productiva entre países de mayor desarrollo como mecanismo que aseguraba la acumulación y expansión económica ante restricciones impuestas por esquemas proteccionistas y políticas nacionales. El contexto reciente indica un replanteamiento basado en estrategias que parten de bloques multinacionales y se soportan en los cambios tecnológicos y de organización industrial que posibilitaron una flexibilización y relocalización de los procesos productivos conforme con una lógica global de expansión económica (Suárez, 1984; Vernon, 1966; González y Ramírez, 1989; Carrillo, 1989; Ranfla y Avilés, 1988)

En el caso específico del bloque norteamericano, uno de los eventos que con énfasis apuntan hacia una formalización de este proceso es el Acuerdo Norteamericano de Libre Comercio (NAFTA). Justamente en el marco de esta dinámica de integración, nos proponemos sefalar la relevancia de las estrategias vinculadas al sector energético con el propósito de valorar algunas de sus implicaciones regionales. Derivadas éstas en una expresion concreta tanto sectorial como territorialmente, interesa identificar elementos que faciliten una interpretación de los intercambios comerciales de energía en la frontera méxico-estadounidense.

Algunos estudios han recalcado aspectos financieros concomitantes al proceso de negociación trilateral. Un informe de la Organización para la Cooperación y el Desarrollo Económico (OCDE, 1992) elaborado por Albert. Fishlow y Stephan Haggard intitulado "Los estados Unidos y la regionalización de la economf́a mundial", asegura que más que facilitar el comercio, es inversión lo que busca México. "Los flujos de inversión que necesita atraer México a su economía son el impulso dominante para que busque un tratado norteamericano de libre comercio" (El Financiero, 5 de agosto de 1992), 
El estudio establece que para México el capital es importante por dos razones. Primero, porque necesita pagar importaciones para sostener su crecimiento y segundo, por la transferencia de tecnología. Ambos elementos se exacerban ante lo que será la característica de los movimientos del capital internacional en la década de los noventa. La propuesta es que los nuevos recursos adoptarán "predominantemente la forma de inversión extranjera directa en lugar de créditos privados o públicos, como se dio en los setentas" (El Financiero, 5 de agosto de 1992).

\section{Posiciones en los tres países}

\section{a) Perspectivá estadounidense}

\section{Los empresarios}

Una visión relevante sobre el papel del sector energético en la negociación comercial corresponde al empresariado estadounidense. Una encuesta realizada durante 1990 entre importantes miembros de la industria química, revelaba que sus principales intereses se han centrado en los derechos sobre propiedad intelectual, compatibilidad de mercados e inversión extranjera.

En el marco del xxII Foro Nacional de la Industria Química, en octubre de 1990, Harry Mohimann, vicepresidente corporativo de Dow Chemical Company, declaraba que las principales ventajas de México como participante en un acuerdo de libre comercio, serían petróleo y energéticos. (El Financiero, 19 de octubre de 1990)

En el comercio bilateral reciente, 9,000 millones de dólares se concentran en la rama de productos químicos, representando más del $17 \%$ de la actividad comercial entre México y Estados Unidos. A pesar de ser el mercado estadounidense el mayor del mundo en esta rama, de contar con plantas productivas superiores y puertos de importancia internacional, sus representantes han insistido en seffalar las ventajas considerables de México en el terreno petrolero y energético. Desde su perspectiva, tales ventajas debieran aprovecharse formando alianzas entre companfías privadas nacionales y extranjeras e incluso con el gobiemo.

El reconocimiento del desarrollo desigual entre ambos países posibilitaría acuerdos de beneficio mutuo. "A Estados Unidos le gustaría grandemente tener acceso a los energéticos mexicanos, petróleo y sus derivados; aunque debe haber personas que no desean que el presidente Salinas regrese algo de gran valor. A México le agradará tener acceso al mercado de acero, zapatos, laboral y otros", expresó entonces el 
vicepresidente de esta empresa de la industria química estadounidense (El Financiero, 19 de octubre de 1990).

Opiniones de productores petroleros independientes en Estados Unidos apuntan importantes elementos en el tema. Según Eugene L. Armes, director de la Asociación Petrolera Independiente de América (APIA), "el notorio declive de la producción petrolera de Estados Unidos y su creciente demanda energética, exiguamente dañada por el movimiento recesivo, confirman que las importaciones de energía fósil jugarán un papel vital en la política energética del país". Esto significa que a pesar de las medidas de conservación y otras, Estados Unidos depende cada vez más de las compras externas de petrolíferos mientras el consumo de energía continúa su acelerada tendencia ascendente, pues desde 1983 ha aumentado casi un 14\% (El Financiero, 8 de noviembre de 1991a).

Si bien la dependencia energética no es comparable a la prevaleciente durante los affos setenta, los avances en ahorro de energía declinan debido al excesivo consumo de gasolina. Tan sólo el sector transporte consume un $65 \%$ del crudo importado por los Estados Unidos.

\section{Las organizaciones sociales}

En Estados Unidos no han sido inexistentes ni escasas las opiniones que han cuestionado abiertamente las bondades del acuerdo. Grupos sindicales, ecologistas y de derechos humanos, se aliaron en poderosa coalición "para oponer o condicionar el libre comercio con México". Su activismo y experiencia en el cabildeo, adquirido en enfrentamientos con la industria nuclear y las multinacionales petroleras son conocidos, y se hicieron sentir en diversas etapas de la negociación.

En opinión de Tim Bennet, grupos ecologistas se han opuesto a la expansión de la industria maquiladora fronteriza por sus repercusiones en el medio ambiente, dada la insuficiencia en regulación y cumplimiento ambiental por parte de la inversión extranjera en México. De la misma forma, se ha cuestionado la degradación de los recursos acuíferos compartidos por ambas naciones, aunque también la creciente intensificación del consumo petrolífero y la explotación irregular de los recursos naturales (E1 Financiero, 12 de diciembre de 1990).

\section{La postura gubernamental}

Desde fines de 1990, varios congresistas expresaron su elevada ponderación para la negociación energética en el tratado. Se llegó a señalar que la trascendencia de esa discusión vuelve insignificante cualquier 
observación relacionada con los acontecimientos políticos internos en México. La Casa Blanca ha expresado en diversas ocasiones, su completa aprobación al manejo de la política económica en la administración del presidente Salinas de Gortari.

En noviembre de ese año, Bill Richardson, diputado congresista del estado de Muevo México, argumentaba la necesidad de una mayor labor de convencimiento hacia legisladores estadounidenses por la parte mexicana de la negociación. Con ello se buscaría evitar que la cuestión pudiera "convertirse en tema fundamental de las elecciones presidenciales en Estados Unidos", lo cual, de cualquier modo, resultó inevitable (El Financiero, 26 de noviembre de 1990).

En ocasión del clima de tensión mundial e incertidumbre generado por el conflicto bélico en el golfo Pérsico, particularmente del riesgo de "una súbita disminución en el suministro de crudo proveniente de esa región", resurge sin ambages, a principios de 1991, por parte del Departamento de Energía de Estados Unidos, la propuesta de reintegrar a México al viejo plan de garantizarse fuentes de abasto seguras y confiables.

Con ese propósito, fue anunciado, desde mediados de enero de 1991, el viaje a México del secretario de energía, James Watkins. Funcionarios del Departamento de Energía y de la embajada de Estados Unidos en México revelaron el interés de su país en desplazar su dependencia energética hacia países seguros, como México y Venezuela, país que también fue incluido en el itinerario del funcionario estadounidense.

De acuerdo con cifras proporcionadas por el Departamento de Energía de los Estados Unidos, la producción estadounidense experimenta una etapa de plena declinación. La tendencia de sus importaciones energéticas se encuentra en constante crecimiento, el que sólo se interrumpe en coyunturas en donde lo permiten los elevados precios alcanzados por los combustibles.

En noviembre de 1991, en la ciudad de México, el congresista Jim Kolbe declaraba que durante la reunión presidencial del 14 y 15 de diciembre se negociaría el acceso preferencial de Estados Unidos a los hidrocarburos mexicanos, así como el restablecimiento de contratos de riesgo. Al mismo tiempo, en Houston el subsecretario de Energía, Henson Moore, advirtió que la Casa Blanca seguiría presionando a México para incluir al sector energético en las negociaciones del tratado de libre comercio (El Financiero, 19 de noviembre de 1991).

Esa ocasión, el congresista Kolbe aclaró que "no se trata de buscar la propiedad del petróleo in situ, sino asegurarse un abasto confiable bajo un esquema similar al que se tiene con Canadá, en el cual se especifica que, en caso de crisis energética, Estados Unidos tiene la garantía de ser el 
primero en la línea de suministros". El subsecretario de Energía, precisó en cambio, que la garantía sobre el abasto sólo podría asegurarla la propiedad sobre los recursos. "Por ello debemos insistir en que desaparezcan los límites a la inversión, así como a la compra y venta de servicios y productos en México", afirmaba el funcionario ante asistentes a la Conferencia Interamericana de Petróleo y Gas. De hecho - se ufanaba-, existe de algún modo ya una relación de libre comercio entre la parte norte del mercado mexicano y los productores de gas del sur de Estados Unidos, concretamente, con los texanos, "que cada día venden más y más gas natural a las empresas mexicanas" (El Financiero, 19 de noviembre de 1991).

A fines de 1991, la representante comercial de la Casa Blanca, Carla Hills, insistía en que el petróleo y sus productos derivados constituyen un $25 \%$ del intercambio bilateral, por lo que en las negociaciones del tratado con México la administración Bush buscó "tanta liberalización como fuera posible" de ese sector.

Versiones de fuentes cercanas a la negociación, en la entrevista BushSalinas de diciembre de 1991, señalaron que el mandatario estadounidense habría planteado que para Estados Unidos lo más importante del tratado sería su contenido y "calidad". Eso parecía indicar que Bush propuso la necesidad de concesiones adicionales para el proyecto de acuerdo enviado al congreso (El Financiero, 8 de enero de 1991).

Con hermetismo, funcionarios de Estados Unidos, México y Canadá celebraron en enero de 1992 reuniones en Washington, D.C. en esfuerzos por concluir un primer borrador del tratado. Algunas discrepancias identificadas aunque no resueltas entonces, fueron la apertura del sector energético mexicano, la participación privada en petroquímica básica, reglas de origen en rubros textiles y automotriz, y prácticas de dumping (El Financiero, 9 de enero de 1992).

En junio, la controversia sobre el tema energético prevalecía en las negociaciones. La situación en la mesa de energéticos continuaba sin mayores avances, a pesar de que algunos reportes de prensa indicaron lo contrario. Los negociadores estadounidenses, sin embargo, mostraron renovado optimismo cuando - debido a la explosión en Guadalajarala posición "intransigente" de Petróleos Mexicanos se debilitó considerablemente (El Financiero, 4 de junio de 1992).

The Oil Daily informó que "Herminio Blanco había quitado la mesa de trabajo a los negociadores para hacerse cargo de ella personalmente". Según la fuente, a la luz del desastre de Guadalajara, el gabinete económico había llegado a la conclusión de que era necesario abrir el sector petrolero a la inversión extranjera, pero que para hacerlo, había que 
resolver antes tres problemas: 1) cómo convencer a la opinión pública mexicana, 2) el mejor momento de hacerlo, y 3) buscar alternativas al problema fiscal que traería para el Estado mexicano la apertura de Pemex (El Financiero, 4 de junio de 1992).

En julio, el Wall Street Journal indicó que "Los negociadores estadounidenses del TLC han aceptado en gran medida que México mantenga la exclusividad en su sector petrolero. E.E.U.U. accede ampliamente a las demandas de que México mantenga un control completo de su industria petrolera". Ambos países - junto con Canadá-sostuvieron a fines de ese mes, en México, otra reunión ministerial para avanzar en las negociaciones comerciales (El economista, 22 de julio de 1992a)

Un funcionario estadounidense citado por el diario norteamericano aclaró: "las compañías de E.E.U.U, no pueden explorar, ni producir, ni refinar, ni transportar, ni distribuir al mayoreo, ni vender al menudeo petróleo mexicano" (El economista, 22 de julio de 1992a).

Thad Grundy, representante del gobierno de Bush durante la primera mitad de 1992 en las negociaciones de la mesa de energía, había declarado apenas unos días antes: "Estados Unidos ve en México una fuente segura de abasto de petróleo, por lo que el tema es la parte medular del tratado de libre comercio. El libre comercio beneficiará a los tres paises sin duda, pero la 'clave de todas las negociaciones' es el tema de la energía", (El financiero, 10 de julio de 1992a).

En la conferencia "Planning for North American Free Trade", organizada por la escuela de leyes de la Universidad de Texas, el ahora ex negociador aseguraba que en Estados Unidos "hay mucho apetito por el petróleo mexicano y eso aumentará en el futuro cercano, porque la producción de mi país está cayendo y lo seguirá haciendo". Actualmente, "la producción de Estados Unidos es tres veces más grande que la de México, pero en éste la tendencia es al incremento, mientras lo contrario ocurre al norte de la frontera" (El financiero, 10 de julio de 1992a).

\section{b) Perspectiva canadiense}

El gobierno

Autoridades canadienses parecen haber identificado las restricciones que operan en México para un desarrollo energético sostenido. En enero se dio a conoces un estudio del Ministerio Canadiense de Energía y Minas que revela cómo a pesar de que las reservas mexicanas de gas son comparables con las canadienses o estadounidenses, la producción es insuficiente para satisfacer la creciente demanda interna, 
por lo que México depende ya de importaciones de Estados Unidos (El financiero, 21 de enero de 1992).

A principios de 1992, en un estudio del Ministerio de Energía y Minas de Canadá, destaca que México cuenta con enormes reservas de gas natural y ventajas geológicas comparativas que podrían situarlo en la vanguardia energética del continente en el largo plazo. Según el documento, titulado "Mexican Natural Gas: Potential Impacts on the North American Gas Market", a pesar de la poca exploración de yacimientos de gas, las reservas mexicanas identificadas, tanto las probadas como las aún no descubiertas, son comparables con las de Canadá y Estados Unidos.

Dos factores explicarían la fragilidad y retraso de la industria gasera mexicana: las políticas energéticas gubernamentales y la crónica falta de capitales en el sector.

La política energética mexicana se ha concentrado en la producción de petróleo, y actualmente México tiene una política de no exportación para el gas natural, además de que para desarrollar una verdadera industria gasera y los potencialmente ricos recursos del sector, se requieren grandes inversiones (El Financiero, 21 de enero de 1992a).

La política de Petróleos Mexicanos de concentrar su esfuerzo en la producción de petróleo crudo ha impedido el desarrollo independiente de una industria mexicana del gas natural. En la actualidad ésta depende virtualmente del ritmo de extracción de petróleo crudo. De hecho, "más del $85 \%$ de la producción mexicana de gas es producto aleatorio de la producción de petróleo crudo (gas asociado), cuando en Estados Unidos esta proporción es de sólo 19\%" adviertieron especialistas del gobierno canadiense (El Financiero, 21 de enero de 1992a).

De acuerdo con ese estudio, las reservas probadas de gas natural en México ascienden a 73 billones de pies cúbicos, volumen equiparable a los 79 billones de pies cúbicos de reservas "comerciables" con que cuenta actualmente Canadá. No obstante esa potencial riqueza, la industria nacional de gas natural se encuentra en un estado de deterioro que podría resultar irreversible si no se inyectan nuevos capitales. Según expresan diversos analistas, "la industria gasera mexicana apenas puede compararse con la situación que vivía la industria canadiense o la estadounidense en los años 50 [...] Pemex tiene pocos incentivos para construir nuevas estructuras o destinar inversiones a la extracción de gas, y quizá no pueda competir con la capacidad instalada de gasoductos con que cuenta el sur de Estados Unidos" (El Financiero, 21 de enero de 1992). 


\section{Los empresarios}

El sector privado de Canadá, desde las reuniones iniciales, insistió en la inclusión de los tres pafses en la negociación con el fin de garantizar un trato que beneficie equitativamente a las inversiones de las tres naciones.

Timothy Page, vicepresidente intemacional de la Cámara Canadiense de Comercio, afirmaba, en enero de 1991, que:

la comunidad de negocios canadiense cree que las negociaciones deben ser trilaterales. La agenda de negociaciones debe ser amplia y no restringir oportunidades a inversionistas competitivos en telecomunicaciones, maquinaria pesada, agroindustria, transporte urbano, recursos naturales, servicios financieros, actividades forestales y mineras (El Financiero, 12 de agosto de 1991).

En esa ocasión, el funcionario, aceptó ampliar su punto de vista exclusivamente en el tema de recursos naturales y petróleo para sefialar. "Nosotros entenderíamos perfectamente que en una negociación trilateral cada parte tendrá temas que no quiera ver negociados" (El Financiero, 12 de agosto de 1991).

La posicion del sector financiero puede identificarse con lo expresado por el Departamento de Economfa del Banco de Montreal en un reporte dado a conocer a mediados de 1991. En él se destaca "una amplia liberalización en los sectores de energia y servicios, un completo y seguro sistema sobre reglas de origen, y una moderada liberalización en el sector agrícola", como aspectos a considerar en el establecimiento del tratado trilateral. Dichos sectores interesan a las tres naciones, aunque igualmente signifiquen "puntos sensibles" en general (El Financiero, 12 de agosto de 1991).

El documento analiza cómo podría quedar el tratado trilateral comparado con el acuerdo vigente entre Estados Unidos y Canadá. Indica que para los tres países la vigencia del tratado es una cuestión de "estrategia" nacional frente a la intensa competencia existente por inversión, mercados y ventajas comparativas en la globalización de la economía.

En cuanto al sector energético - destacó el estudio-podría negociarse como lo hicieron antes los dos del norte, para garantizar a México su propiedad de recursos aunque se permita a los otros dos el acceso a otras áreas del propio mercado. Con ello, la apertura energética sería menor comparada con la establecida en el acuerdo bilateral de Estados UnidosCanadá, aunque se alentaría la inversión tecnológica y el intercambio comercial en petroquímica. 
En el plano académico, algunas preocupaciones se han centrado en el aspecto general de las repercusiones sobre políticas públicas y restricciones a la política exterior. En este sentido, por ejemplo, algunos estudios han indicado que el acuerdo de libre comercio de Canadá con Estados Unidos a pesar de haber generado beneficios económicos tuvo, a su vez, impactos negativos, Los formuladores de políticas canadienses parecen haber subestimado preocupaciones nacionalistas, y a los estadounidenses les ocurrio lo mismo. La integración económica tuvo implicaciones adicionales en consideraciones de orden militar estableciendo nuevos límites a la política exterior canadiense (Stewart, 1991).

Maxwell A. Cameron de la Norman Patterson School of International Affairs de la Carletton University en Ottawa, ha seffalado que una perspectiva de política pública sobre las negociaciones comerciales no logra capturar la 16 gica esencialmente política del acuerdo. Los estados-nación actúan tanto en búsqueda de beneficios económicos como de poder politico (Cameron, 1991).

En un estudio auspiciado por el Centro de Estudios Internationales de Toronto, titulado "Free Trade in Energy Among the US, Canada and Mexico: State-of-Play and Prospects", G.C. Watkins y S.M. Jones, sefialan que la negociación del rubro energético en el tratado norteamericano tendría considerables repercusiones regionales e incluso de carácter mundial (El financiero, 4 de agosto de 1992a).

Según esta visión, para México podría significar mayor capacidad de manejo de su petróleo y abasto más eficiente de crudo y gas hacia Estados Unidos y Canadá. Con la negociación del sector en el tratado habría mejores oportunidades para utilizar el petróleo mexicano en refinerías de Estados Unidos y de Canada. Esto implicaría mayor y mejor instalación de plantas, dando preferencia a los crudos duros mexicanos. A su vez, el acuerdo podría brindar oportunidades a Estados Unidos y quizás a Canadá para un "sustancial" movimiento de gas hacia México a través de instalaciones de gasoductos.

'Una posición en el mismo sentido es la del Instituto para la Economía Internacional (IIR), al estimar que "el eventual tratado de libre comercio de Norteamérica producirá un incremento de alrededor de $30 \%$ en el intercambio de bienes y servicios entre México y Canadá". Gary Clyde Hufbauer y Jeffrey J. Schott, en su reporte "El TLC: aspectos y recomendaciones" sostienen que las exportaciones mexicanas a Canadá podrían aumentar un $20 \%$ para 1995 , alcanzando una cifra cercana a 1,762 millones de dólares respecto a 1989. Las exportaciones canadienses, que en 1989 fueron de 522 millones de dólares, podrian crecer un $40 \%$ los 
próximos tres afios, ascendiendo a 730 millones de dólares (El funanciero, 3 de marzo de 1992).

Hufbauer y Schott indicaron que gran parte del comercio bilateral México-Canadá "probablemente se derivará de las operaciones de ensamblaje en México que importan equipo y partes canadienses y exportan artículos manufactureros. Los principales rubros de comercio bilateral Canadá-México son maquinaria y equipo de transporte, bienes manufacturados, alimentos, combustibles minerales, lubricantes, bebidas y tabaco (El financiero, 3 de marzo de 1992).

\section{c) Perspectiva mexicana}

\section{Los académicos}

El sector académico mexicano ha discutido y evaluado algunos escenarios e implicaciones de la negociación trilateral. En particular, destacan los aspectos que podrían afectar negativamente algunas expectativas nacionales en sectores clave como es energéticos. Este es el caso de un grupo de académicos de la Universidad Nacional Autónoma de México, encabezados por la profesora María Teresa Gutiérrez quienes elaboraron un estudio denominado "La integración comercial de México a Estados Unidos y Canadá. ¿Alternativa o destino?". En relación con el acuerdo vigente entre Estados Unidos y Canadá sefhalan puntos vulnerables para Canadá en agricultura, energía, automotriz, servicios e inversiones ( $E I$ financiero, 28 de enero de 1991).

En energía, por ejemplo, el artículo 409 concede a Estados Unidos derechos sobre la energía y recursos energéticos de Canadá en condiciones similares a las de los últimos tres años. El consumidor estadounidense no puede sujetarse a un precio mayor, pues esto se entendería como tasa discriminatoria. Tampoco podría otorgarse ayuda federal o provincial a quien desee invertir en una región, considerando esto como un subsidio injusto en contra de los Estados Unidos.

El referido estudio consideró que a pesar de las declaraciones oficiales, resultarfa contradictorio que el petróleo mexicano no fuera incluido en las negociaciones, pues el acuerdo dificilmente podría excluir aspectos que interesan a Estados Unidos y esos son, precisamente, petróleo y agricultura.

Otro elemento digno de atención es la cláusula de "tratamiento nacional" - también firmado con Canadá - que vuelve factible la competencia no tanto entre nacionales sino con empresas del país signatario. México tiene sectores débiles que tendría que proteger y dejar completamente fuera del acuerdo (El Financiero, 28 de enero de 1991). 
En opinión de académicos, desde principios de 1992 era claro que Estados Unidos realizó una estrategia paralela e independiente a las negociaciones del tratado para asegurar mediante convenios especfficos que el sector energético mexicano quedase abierto a la inversión estadounidense (El Financiero, 6 de abril de 1992).

Para la administración estadounidense, con o sin tratado, el capital de ese país intervendrá en la industria petrolera mexicana, dado que serán las propias necesidades financieras de PEMEX las que generarán modificaciones constitucionales y la demanda por capital y tecnologia estadounidense.

Lo anterior se seffala en un análisis del Centro de Investigaciones sobre Estados Unidos de América (CISEUA) de la UNAM, realizado por Rocío Vargas Suárez, acerca del papel de los energéticos en el tratado de libre comercio.

Seguin la investigadora, presiones políticas ocasionaron que el gobierno estadounidense optara por otorgarle confianza al gobierno de México, para que éste pudiera determinar las modalidades y ritmo de incorporación de los energéticos en una negociación bilateral que no necesariamente tenga que ser el TLC. Se trataria de un acuerdo que permita institucionalizar las relaciones energéticas sin introducir enmiendas a la Constitución, pero que garantice un ritmo de producción y exportación de crudo hacia Estados Unidos a partir de ciertos apoyos financieros.

Antecedentes personales de Bush en el negocio petrolero explicarian su apoyo a empresas de ingenierfa de servicios - de perforación bajo contrato-, localizadas al sur de Estados Unidos, que obtendrían beneficios a partir de compras de tecnología y servicio por Petroleos Mexicanos (El Financiero, 6 de abril de 1992).

La caída de las reservas petroleras de 72,500 millones de barriles en 1983 a 66,450 millones en 1990 , junto con un aumento en el consumo nacional, generaron temores de una merma en el suministro futuro al mercado de Estados Unidos. De acuerdo con estimaciones estadounidenses, de continuar esta tendencia, México se convertiría en importador de petróleo en 2004. Otros indican que aún con inversiones masivas del exterior, México sería importador neto en 1997. Incluso, organismos como el "Overseas Development Council", senalaron que "el estancamiento de Pemex es la razón por la cual el tema de los hidrocarburos "sería" esencial en las negociaciones del tratado de libre comercio".

\section{Los empresarios}

Integrantes del sector privado mexicano, especialmente de la pequeña y mediana industria, se expresaron en favor de un enfoque precavido y fundamentado para la cuestión energética. Un diagnóstico elaborado por 
la Cámara Nacional de Manufacturas Eléctricas, establece que "đadas las radicales asimetrías tecnológicas y económicas entre empresas mexicanas y estadounidenses de la industria de manufacturas eléctricas es imprescindible que en la negociación del tratado de libre comercio se establezca el principio desigual para desiguales, como premisa principal para evitar la quiebra de un gran porcentaje de las empresas nacionales" (El Financiero, 22 de mayo de 1991).

Por ello "de ninguna manera las negociaciones del tratado comercial deben incluir el capitulo referente a la Ley de Compras del Gobierno Federal, que rige las adquisiciones de Pemex y la Comisión Federal de Electricidad", pues abrir este mercado representarfa condenar a las industrias mexicanas a entrar a una fase de deterioro que dificilmente podrían superar.

En opinión de la organización, "ello equivaldría a renunciar a la utilización de uno de los principales instrumentos de fomento a la industria nacional con que cuenta el gobierno federal", pues el impacto de la demanda del sector público en el área de bienes de capital, es determinante en la conservación de la viabilidad económica del sector eléctrico (El Financiero, 22 de mayo de 1991).

En el marco de la negociación petrolera, el sector privado también ha manifestado posiciones de franco cuestionamiento a los intereses del país del norte.

En diciembre de 1991, Emilio Vega Lazo, consejero del Centro Empresarial de Jalisco (CEJ), al estimar que las negociaciones bilaterales habían entrado en un terreno peligroso, denuncio: "El gobierno estadounidense por fin se ha descarado y ha mostrado que lo que quiere de México en el marco de un tratado de libre comercio es apoderarse del petróleo mexicano, por lo cual no es de extrañar que continúen presionando a nuestro país para que se le otorguen "concesiones políticas importantes",

En diversos momentos llegó a considerarse que la formalización del tratado dependería de la reelección de Bush. Según expresaron analistas bancarios a principios de 1992, "Si el tratado no se firma, o no se considera bien negociado, las reservas de divisas del Banco de México no aumentarán este afio y el crecimiento no sería tan espectacular como si el documento es signado por los tres países. Quizás haya una desaceleración económica y no se logre el 3.8 o 3.9 de crecimiento del PIB, previsto para 1992" (El Financiero, enero 22 de 1992).

Los analistas bancarios consideraron que el punto más delicado sería la negociación de energéticos, en donde los estadounidenses buscaban obtener importantes ventajas. A medida que México concedían espacio a la inversión extranjera en este renglón, la firma del tratado sería más fácil. 


\section{Partidos politicos}

Las organizaciones políticas, a falta de mayor certidumbre relacionada con aspectos que pudieran incidir sobre las condiciones de vida y laborales para los mexicanos, en lo fundamental, han concentrado su interés en la vigilancia de la posible afectación al espiritu del texto constitucional.

El 17 de diciembre de 1991 Cuauhtémoc Cárdenas Solórzano, dirigente del Partido de la Revolución Democrática (PRD), señalaba la necesidad de mayor información sobre las entrevistas presidenciales relacionadas con las negociaciones del tratado, para conocer el grado de avance y compromisos que se dieron durante las mismas.

En esa ocasión, el dirigente argumentaba que con objeto de acelerar la firma del TLC era evidente que el gobierno mexicano habrla puesto en la mesa de negociación la oferta del petróleo, el que no debería ser incluido en las pláticas. La propuesta de su partido en tomo del TLC fue la de no incluir al petróleo, dándole un manejo distinto al que se le viene dando; esto es, utilizarlo para satisfacer demandas internas y en el caso de las exportaciones limitarlas a productos petroquímicos y refinados (El Financiero, 17 de diciembre de 1991b).

\section{La postura gubernamental}

En junio de 1991, el secretario de comercio mexicano, Jaime Serra Puche, reiteraba a dirigentes del Congreso del Trabajo que México no negociaria "petróleo, ferrocarriles, telégrafos, electricidad ni petroquímica básica", durante una reunión en la que la dirigencia de la organización solicitaba formalmente un mayor número de representantes obreros en el cuerpo de asesores de la unidad negociadora mexicana (El Economista, 28 de junio de 1991).

En agosto de 1991, el secretario de comercio establecía la posición mexicana en relación con el petróleo. "En el campo de energéticos, la posición mexicana es firme e invariable y ha sido aceptada por las contrapartes: las disposiciones constitucionales sobre la materia son intocables". Aclaró que, aun en caso de que México otorgue contratos de servicios de explotación y exploración petrolera, "el país no va a compartir riesgos ni otorgará beneficios sobre el petróleo encontrado" (El Financiero, 28 de agosto de 1991).

Inicialmente, se había negado la inclusión del tema en la agenda de discusiones. Posteriormente, se aceptó que forma parte de la misma como subgrupo de energéticos (petróleo y electricidad). 
En opinión de diversos analistas, la recesión estadounidense y la presión electoral en ese país pusieron de nueva cuenta a la industria petrolera mexicana en la mesa de negociaciones a principios de 1992.

"Si se quiere que el tratado se firme antes de las elecciones, México tendría que ofrecer al gobierno estadounidense concesiones importantes, entre ellas la apertura de la industria petrolera a la inversión extranjera, para ofrecer un acuerdo vendible", declaraba a principios de 1992 Abel Beltrán del Río, presidente de la consultoria Ciemex-Wharton (ElFinanciero, 28 de agosto de 1991).

Por su parte, el secretario de comercio de México sef̂aló en enero, que en el TLC hay un capítulo dedicado a la energía, "en que se analizan los flujos comerciales", pero aclaró que "ninguna de las restricciones constitucionales en la materia serian sujetas a negociación".

El jefe de la oficina negociadora, Herminio Blanco, entrevistado en esa ocasión, decía que "en el capítulo sobre energéticos se está viendo todo lo relacionado con importaciones y exportaciones". "De petrolíferos?", se le pregunt6, y su respuesta fue: "es todo lo que puedo decir" (El Financiero, 23 de enero de 1992).

La representante comercial estadounidense Carla Hills, declaró a periodistas en Washington que si bien se respetarian las restricciones constitucionales mexicanas respecto a hidrocarburos, "la energía es un punto muy importante para nuestra economía y hemos estado discutiendo el tema con ese pais". No es difícil suponer que en febrero el tema continuó en la mesa de discusiones. Los secretarios de comercio de México, Canada, y la representante comercial estadounidense, sostuvieron reunión privada ese mes en Maryland, "para revisar avances en la negociación y destrabar nudos de conflicto" (El Financiero, 23 de enero de 1992).

En julio de 1992, fuentes oficiales informan que en el contexto del tratado, el gobierno mexicano permitiría la importación de gasolina y diesel de Estados Unidos y Canadá; de acuerdo con ello, se reformaría la Ley del Impuesto sobre Producción y Servicios (El Financiero, 10 de julio de 1992).

Grupos negociadores del Tratado Norteamericano de Libre Comercio continuaron en agosto con la redacción de textos de los 18 temas, sin incluir aún energía, en la expectativa de terminarlos en las semanas siguientes. Mientras tanto, en Washington, seguían los trabajos en torno al sector automotriz, energía y compras gubernamentales (El Financiero, 6 de agosto de 1992b).

Durante los trabajos de la VII reunión ministerial en Washington -la más prolongada de todas - los ministros de comercio mexicano y canadiense, así como la representante comercial de Estados Unidos, no hablan 
podido superar el escollo representado por el sector energético, pues los últimos persistieron en la demanda de que México liberase el petróleo y asegurara el abasto de crudo.

Fuentes allegadas comentaron: "del punado de temas sobre los que concentran tiempo y esfuerzo Hills, Serra Puche y Wilson, la apertura de Petróleos Mexicanos a compañías estadounidenses y canadienses proveedoras de equipo y servicios petroleros ha convertido la mesa de compras gubernamentales en una verdadera arena de boxeo político" (El Financiero, 11 de agosto de 1992).

La propuesta de México de reservar a la industria mexicana $80 \%$ de las compras que efectúe Pemex y Comisión Federal de Electricidad (CFE), se modifić a $55 \%$ durante los primeros ocho años del TLC, al cabo de los cuales bajará a $30 \%$. La propuesta de México consideraba que las empresas mexicanas mantuvieran el derecho a competir en la porción de los contratos abiertos a licitación extranjera. Sin embargo, Estados Unidos insistió en que México reservara $30 \%$ a su industria, llegando a ese porcentaje en tres años. Además, Estados Unidos demandó que la empresa mexicana no participe en el $70 \%$ restante.

Estados Unidos tampoco pareció quitar el dedo del renglón en lo referente a seguridad de abasto petrolero en tiempos de crisis. Personas cercanas a las pláticas dijeron que los negociadores canadienses volvieron a amenazar con que si México no cede en esto, Canadá renunciará a la cláusula de abasto seguro en el convenio bilateral con Estados Unidos, medida considerada por muchos canadienses como entrega de soberanía.

Según fuentes oficiales en Washington, a fines de agosto de 1992 , cuando los negociadores de los tres gobiernos daban toques finales al compacto trilateral, "en materia de energéticos se habrían superado los obstáculos con estricto apego a la Constitución Mexicana" (El Financiero, 12 de agosto de 1992).

La primera impresión del proceso fue que los negociadores mexicanos habrían defendido la soberanía actuando con apego estricto al documento constitucional. Sin embargo, un común denominador en el manejo de información hacia la opinión pública fue la ausencia de detalles y la vaguedad reiterada en el tema de energía. Se omitió lo sustancial en un asunto de gran importancia. Los negociadores pretendieron implicar la cuestión del abasto seguro con restricciones constitucionales, siendo más bien un asunto de intercambio comercial, que no guarda relación alguna con la Constitución Mexicana.

Si bien México no se obligó a asegurar el abasto estratégico, sí suscribe un compromiso moral de ofrecerlo a Estados Unidos antes que 
a cualquier otro comprador en épocas de crisis, tales como guerras o eventualidades en el mercado.

No se explicó con amplitud en qué consiste el apego a la Constitución. Comentaristas de The Oil Daily y The Petroleum Intelligence Report, lo definieron de este modo en Washington "parece que se quisiera ocultar con la reiteración de vaguedades los detalles implícitos en el tratado". Jim Riley, especialista en seguridad nacional, resumió con agudeza: "El abasto estratégico de petróleo de México a Estados Unidos es implícito. Lo implícito quedó explícito. Los bienes conyugales se separan sólo si la pareja se separa. Pero mientras tanto, ambos los pueden usar indistintamente" (El Economista, 13 de agosto de 1992).

En conferencia de prensa en el Instituto Cultural Mexicano de Washington, el 13 de agosto de 1992, Serra Puche ratificaba que el TLC en materia energética, cumple con los cinco puntos que el gobiemo mexicano habla indicado: no habrá contratos de riesgo, ni cláusulas de garantía de abasto, ni importación de gas natural sin autorización de Pemex y no se establecerán en el país gasolinerías extranjeras. Rechazó que hubieran existido presiones para completar el acuerdo, negando la posibilidad de su renegociación en caso de registrarse cambios políticos en Estados Unidos - Canadá. "México terminó la negociación", aseguró (El Economista, 13 de agosto de 1992).

\section{DESEMPEÑO RECIENTE DEL SECTOR ELÉCTRICO Y DE LA PRODUCCIÓN DE GAS NATURAL EN MÉXICO}

\section{Posición financiera y productiva del sector eléctrico}

\section{a) Creciente dependencia del financiamiento externo}

Un elemento con que se ha justificado progresivamente la participación externa en sectores estratégicos, ha sido la escasez de fondos domésticos para llevar a cabo programas de expansión en la medida necesaria.

En mayo de 1991, CFE informaba del retraso de casi dos años en la llegada de recursos provenientes del Banco Mundial y del Banco Interamericano de Desarrollo, provocando serios problemas a los programas de construcción de obras y proyectos del sector eléctrico. El efecto financiero fue tal que las empresas del sector eléctrico suspendieron temporalmente la construcción de centrales generadoras con capacidad promedio de más de 2,000 megawatts, en los primeros dos affos de la presente administración. 
La vigencia del Programa de Obras e Inversiones del Sector Eléctrico (POISE) 1989-1994 dependía, en gran medida, de esos 760 millones de dólares, "mismos que se contabilizaron mucho antes de amarrar las líneas de crédito de los organismos financieros internacionales". Uno de los objetivos trazados por CFB y Compafía de Luz y Fuerza del Centro (CLFC) en su programa de expansión era alcanzar una capacidad instalada de 26,394 megawatts en 1989. La capacidad instalada alcanzada realmente ese afio fue de $24,445 \mathrm{MW}$ (El Financiero, 15 de mayo de 1991).

\section{b) Nuevos argumentos ante el problema}

Acontecimientos asociados a la creciente incapacidad financiera de sectores estratégicos, como el eléctrico, no dejan de provocar inquietud en diversos sectores de opinión en México. En este sentido, algunos partidos políticos expresan su inconformidad con el manejo gubernamental del asunto. "El proceso de descapitalización de la industria eléctrica nacional hace sospechar que para inyectarle recursos el gobiemo federal tiene la intención de privatizarla", sostenfan en julio de 1991 legisladores del Partido Acción Nacional. Manifestaban su franca oposición a esta medida en caso de asemejarse al de Teléfonos de México (El Financiero, 2 de julio de 1992).

Declaraciones del Banco Mundial conforman una posición relevante en la discusión sobre las finanzas del sector eléctrico mexicano. "Privatizar el sector eléctrico de América Latina es la clave para evitar que la escasez energética ahogue el despegue económico de la región", dijoen septiembre de 1991 uno de los vicepresidentes del Banco Mundial en la inauguración de la conferencia de ministros de Hacienda y Energía del área (El Financiero, 6 de septiembre de 1991a).

Shahid Husain, vicepresidente del Banco Mundial para América Latina y el Caribe, seffaló en esa ocasión que "dada la magnitud de las inversiones y la evidente imposibilidad de la mayoria de los países de la región de dedicar recursos fiscales al sector eléctrico, la movilización de capitales privados se convierte en una tarea de primera prioridad" (El Financiero, 6 de septiembre de 1991a).

Los estados latinoamericanos no están en condiciones de cubrir las inversiones requeridas para los próximos cinco años -unos $10 \mathrm{mil}$ millones de dólares-y superar el actual rezago de sus plantas eléctricas. "Una creciente participación del sector privado parecería ser el elemento clave en la solución del problema de la brecha de financiamiento", sostuvo entonces el representante del Banco Mundial. Expresó que el ahogo 
financiero de las empresas eléctricas era "especialmente grave" en naciones en las que durante años se ha descuidado tanto inversión como mantenimiento.

En opinión de algunos sectores, las difíciles condiciones para la expansión del sector favorecen paulatinamente la posibilidad de una privatización. El editorial de un diario de circulación nacional ha comentado:

Hundido en severa crisis económica, descalificado por la comunidad financiera internacional para nuevos créditos, reconocido como el más deficitario del gobierno, presa del sindicalismo que supo imponerle todo tipo de condiciones y ganarse toda clase de canonjias, el sector eléctrico nacional se encamina hacia la privatización.

Se especula que el gobiemo recurriría a los mismos argumentos con que justificó la venta de Teléfonos de México para poner a la venta las dos paraestatales, Comisión Federal de Electricidad y Compañía de Luz y Fuerza del Centro, dada la imposibilidad de lograr la limpia financiera y de recursos humanos que pretendia para no liquidarlas.

Se reconoce como un problema la fortaleza de las dos agrupaciones laborales, ambas renuentes a perder posiciones. Con este panorama sindical y la complicada situación económica de las dos empresas, además del rechazo popular que han despertado las decisiones de hacer que la ciudadanía pague el costo de la indiscutible ineficiencia, el gobiemo encuentra pocas alternativas para sanear el sector eléctrico, por lo que afirman quienes están enterados que en cualquier momento se podría anunciar la privatización de las dos dependencias que se encargan del suministro de energía eléctrica (La Jornada, abril de 1992).

A principios de junio, el Banco Mundial recomienda a México, Belice y países de Centroamérica ajustar al alza los precios de la electricidad, para "reflejar mejor el costo real de la generación". Cuestiona el papel rector del Estado en la industria eléctrica, argumentando que debe haber un alejamiento del modelo autoritario hacia un sistema descentralizado basado en incentivos de mercado (La Jornada, 1 de junio de 1992).

El principio de que la energía es un bien estratégico de servicio público y que la población tiene derecho a percibir un servicio de bajo costo, debe ser transformado por el de la creación de una entidad reguladora independiente que permita redefinir el papel del gobiemo en este sector (La Jornada, 1 de junio de 1992).

El documento del Banco Mundial, firmado por Robert J. Saunders y Enrique Crousillat del Departamento de Industria y Energía, menciona que 
en países en desarrollo el consumo de energía tiende a aumentar debido fundamentalmente a cuatro razones:

a) El fracaso de muchos gobiemos en reflejar incrementos de los precios internacionales de energía en los mercados internos.

b) Gran parte del consumo de energfa, en muchos países, se da en sectores dominados por empresas estatales ineficientes y sobreprotegidas.

c) Las empresas estatales productoras de energía, frecuentemente subsidiadas, no han tenido mayores incentivos para lograr un proceso más eficiente.

d) Por último, mercados de estructuras no comparativas y precios subsidiados de energía han reducido considerablemente los incentivos para actividades tan importantes como la intermediación en la información financiera y sobre opciones tecnológicas para un uso más eficiente de energía (La Jornada, 1 de junio de 1992).

A fines de junio, luego de que el gobierno federal determinó suspender parcialmente el programa nucleoeléctrico, CFE anunciaba la puesta en marcha de un programa de generación carboeléctrica, con que se sustituirá el uso de petróleo como fuente de generación primaria en más de $50 \%$, además de que el basado en carbón aumentará del 7 al 30\% (La Jornada, 29 de junio de 1992).

En el marco de la vin Conferencia del Carbón de la Cuenca del Pacífico, se informó que el carbón constituirá el segundo energético de México tan sólo después del petróleo, pues sus condiciones en el mercado internacional le auguran precios bajos y más estables que los propios hidrocarburos.

La problemática actual del carbón en el país, se refiere fundamentalmente a su ubicación geográfica. Este sería el caso de México, pues además de carecer de este recurso, su principal exportador sería Colombia, aunque países como Japón están interesados en constituirse en su principal abastecedor (La Jornada, 29 de junio de 1992).

Industriales y técnicos de la CFE integrantes de la delegación mexicana en la conferencia dieron a conocer que por ello México ya prepara infraestructura y ordenamiento legal con el fin de convertirse en uno de los grandes importadores de carbón de la época moderna, ya que el aumento de la actual capacidad instalada de electricidad, no se fincará en hidrocarburos. Antes de concluir la actual década México importará un promedio de 16 millones de toneladas métricas de carbón anuales, con lo que termina la trayectoria de autosuficiencia que por más de 100 affos caracteriz6 al país (El Financiero, 1 de julio de 1992). 


\section{e) Visión de autoridades mexicanas}

Funcionarios mexicanos avalan las "nuevas circunstancias" y el reto que significan. Ejemplo de ello, en reunión organizada por el Banco Mundial y la Organización Latinoamericana de Energía, Jose Ángel Guría, subsecretario de Asuntos Internacionales de la Secretaría de Hacienda, destacaba cómo ante la necesidad de sostener el crecimiento del sector eléctrico, "hay que buscar fómulas de financiamiento cada vez más creativas". Hace 25 antos, después del gobierno federal, CFE fue la entidad que primero acudió al mencado intemacional de capitales, colocando bonos en unidades europeas, "no veo ninguna razón para que no pueda explorarse el acceso a mercados internacionales de manera cuidadosa y prudente" (El financiero, 6 de septiembre de 1991b).

Por su parte, autoridades de la Secretaría de Energia, Minas e Industria Paraestatal (Semip) se pronuncian por un mayor esfuerzo de autofinanciamiento mediante incrementos de precios y tarifas. En documento dado a conocer a fines de 1991, se establece que "ante la incapacidad del sector eléctrico para generar sus propios recursos, el gobiemo federal debe continuar la política de incremento a las tarifas, ahorro y uso racional de la energia, importaciones, rehabilitación y modernización de unidades termoeléctricas y reforzamiento de enlaces de la red troncal de transmisión". Al respecto, la SEMIP seflala la urgencia de aumentar precios de la electricidad en términos reales hasta alcanzar una relación unitaria respecto a costos (El Financiero, 8 de noviembre de 1991b).

En 1988 se eliminaron subsidios a industriales, un affo después a comercios y alumbrado público; sin embargo, en consumos residenciales "se decidió adoptar una política de mediano plazo que, en forma gradual y sostenida, corrija cuando menos parcialmente las distorsiones" ( $E l$ Financiero, 8 de noviembre de 1991 b).

Comision Federal de Electricidad parece-haber encontrado en una expansión de capacidad firme para exportacion, un sano mecanismo de financiamiento, en especial para las necesidades de la frontera norte. En diciembre de 1991, el jefe de proyectos de la Unidad Termoeléctrica Presidente Juárez, declaraba: "En los últimos ocho afos México incrementó sus exportaciones de energía eléctrica a Estados Unidos $1,390 \%$, pasando de 14 a 1,960 gigawatts-hora, como consecuencia de los convenios firmados en El Paso, Texas" (El Financiero, 17 de diciembre de 1991b).

De acuerdo con estimaciones de CFB, para julio de 1991, la exportación a Estados Unidos fue de 1,167 gigawatts hora; en tanto que al cierre de diciembre, el fluido electrico mexicano con que se completó el abasto de ciudades fronterizas norteamericanas fue de 793 gigawatts. 


\section{Producción y consumo de gas natural en México}

\section{a) Ascendente demanda interna e importaciones}

El comercio de gas a través de fronteras internacionales representa cerca de un $14 \%$ de la producción en el mercado mundial. Según Oil \& Gas Journal, la tendencia debe continuar al alza durante décadas debido a la apertura de las fronteras políticas y económicas en naciones de Europa del Este y América Latina. El abastecimiento mundial de gas provendrá mayoritariamente de países en desarrollo (El Financiero, 4 de julio de 1991a).

A pesar de que en 1990 México había logrado una reducción de $6.8 \%$ en importaciones de gas natural y un incremento del $2.2 \%$ en producción; un año después, en 1991, el consumo de gas en México registró un fuerte crecimiento. De acuerdo con cifras de Petróleos Mexicanos, hasta abril de 1991 las importaciones de gas se dispararon más de $168 \%$, pasando a 114 millones de pies cúbicos diarios después de que en 1990 se situaron en sólo 42.5 millones (El Financiero, 4 de julio de 1991b).

Considerando nuevas condiciones para el sector petroquímico y los proyectos por reducir la contaminación ambiental es probable que la producción gasera mexicana resulte insuficiente para satisfacer la creciente demanda interna.

Si bien la producción llegó a incrementarse, analistas y funcionarios del sector consideran que la planta productiva ha operado al máximo de su capacidad instalada. Los ritmos de explotación se reflejan en una derrama de reservas probadas de gas natural, que en $\propto$ cho afios perdieron unos 1,202 millones de barriles. Estas pasaron de 15,404 millones de barriles en 1983, a 14,202 a principios de 1991.

De acuerdo con estimaciones de la Independent Petroleum Association of Canada (IPAC), durante 1991 Pemex importó -a través de su filial Petróleos Mexicanos International (PMI) - un volumen diario de 100 millones de pies cúbicos de gas texano, lo que representa un incremento de más de $135 \%$ respecto a compras realizadas en 1990 (El Financiero, 4 de julio de 1991).

Gerry Protti, director ejecutivo de IPAC, sefial6 que en 1992 las importaciones mexicanas alcanzarán niveles cercanos a 400 millones de pies cúbicos diarios, requeridos para abastecer nada más, "las crecientes necesidades de abasto de las industrias situadas en el norteño estado de Chihuahua". En su opinión, al convertirse México en importador neto de gas natural ayuda a disminuir la ardua competencia entre empresas gaseras de Estados Unidos y Canadá, que enfrentan una de las peores crisis de su 
historia debido a los bajos precios en el mercado norteamericano ( $E l$ Financiero, 4 de julio de 1991b).

La firma del tratado comercial entre los tres paises "sería una excelente noticia para los productores canadienses y estadounidenses. Los actuales problemas que enfrenta la industria están en relación con el exceso de capacidad instalada, de modo que cualquier situacion que estimule el consumo es un bono para la industria", afirmo el funcionario de IPAC. (El Financiero, 4 de julio de 1991b).

Durante los primeros siete meses de 1991, Petróleos Mexicanos registró un déficit de 130 millones de dólares en su balanza comercial externa en el rubro de productos petrolíferos y petroquímicos. En el desglose de la información preliminar se puede apreciar que el comercio exterior de productos petroliferos y gas natural ha entrado en una fase critica, tanto en lo concerniente a ventas extemas como a importaciones (El Financiero, 18 de septiembre de 1991).

En diciembre de 1991, José Luis Aburto, subsecretario de energía, afirmaba que las importaciones de gas natural se incrementaron en más de $700 \%$, pasando de 40 a 3,000 millones de metros cúbicos diarios entre 1990 y 1991. No se detuvo en agregar que estas importaciones diarias de gas natural significaron un ahorro importante para el pais, ya que los precios del energético en mercados internacionales están a la baja, tratándose de un combustible útil y eficiente que puede usarse con una gran ventaja económica (El Financiero, 13 de diciembre de 1991).

Por su parte, la Cámara Nacional de la Industria de la Transformación, ha advertido que ante el continuo descenso de las reservas probadas de hidrocarburos - cuyo nivel ha sido el más bajo en los últimos 10 añoses imprescindible fortalecer la inversión pública en la industria petrolera, particularmente, en procesos de refinación y transformación y no sólo en perforación y extracción de recursos.

La importancia de incrementar los recursos públicos destinados a inversión en diversas ramas industriales se acrecienta debido al deterioro del gasto de inversión en capacidad instalada, que se ha rezagado y por tanto no es posible garantizar el abastecimiento adecuado y oportuno de energéticos a industriales mexicanos. Por ello, pese a que en los últimos años se observan aumentos en los montos de producción de crudo nacional, su nivel es insuficiente para proveer adecuadamente las demandas externa $\mathrm{e}$ interna, con lo que se ha tenido que echar mano de las reservas. "En este contexto, resulta paradojico que mientras Estados Unidos busca acrecentar sus reservas y garantizar su aprovisionamiento, México las comercializa" (El Financiero, 23 de diciembre de 1991), 
La producción nacional de gas natural cayó a su nivel más bajo en los 12 últimos afios entre enero y abril de 1992, situándose en 3,233 millones de pies cúbicos diarios (El Financiero, 7 de julio de 1992).

Pemex se encuentra imposibilitado para incrementar significativamente la producción nacional de gas por dos razones: primero, porque el $80 \%$ de ésta es gas asociado; y segundo, por la insuficiente afluencia de recursos al sector. Hasta hoy, la política energética se centra en la producción de crudo, y el gas natural ha sido considerado como un hidrocarburo secundario, de tal forma que la industria gasera "tiene que competir con el sector petrolero en la canalización de recursos".

Por otra parte, según Francisco García Hemández, del Instituto Tecnol6gico y de Estudios Superiores de Monterrey, México importa actualmente entre 300 y 400 millones de pies cúbicos diarios de gas natural del sur de los E.E.U.U. para satisfacer la demanda de los estados fronterizos del Norte.

A la luz de los efectos contaminantes propiciados por la industria se ha originado una rápida y acelerada sustitución de combustibles convencionales por gas natural, no sólo por la alta eficiencia en transferencia de calor sino también por la combustión más limpia de éste. Debido a ello, diversas proyecciones privadas apuntan que en los próximos cinco afíos el consumo de gas natural en México podría dispararse en un rango de mil a 2 mil millones de pies cúbicos diarios (El Financiero, 7 de julio de 1992).

\section{b) Apertura y segmentación del mercado}

En junio de 1991 declaraciones del titular de la Subdirección de Petroquímica y Gas Natural, confirma que las compras mexicanas de gas natural procedente de Texas ascendieron a un promedio de 200 millones de pies cúbicos por día. Según advirtio el funcionario, los meses siguientes, México seguiría aumentando sus compras de gas natural a empresas texanas, presionando al alza los precios del combustible en mercados estadounidenses. Hizo saber que Pemex estaba buscando abastecer a la industria del norte del país por medio de importaciones, debido a que se trata de "una zona naturalmente inclinada a consumir el gas procedente de Estados Unidos ...(zona que) está muy cerca de los campos texanos de gas natural" (El Financiero, 16 de agosto de 1991).

El funcionario reveló que Pemex ya consideraba "la posibilidad de dividir a México en el corto plazo en dos amplias zonas" de consumo, de suerte que se crearían la región norte y la región centro-sur para planificar el abasto de gas natural en la república. La primera se abre a la competencia de gaseras y distribuidoras estadounidenses y canadienses, en tanto que la segunda "continúa siendo abastecida por el gas producido internamente". 
Crecientes necesidades de gas natural en el norte del país y limitaciones estructurales de la industria gasera mexicana, desataron una enconada competencia entre las compafías estadounidenses, que desplazan a Petroleos Mexicanos del promisorio mercado fronterizo (El Financiero, 31 de octubre de 1991).

San Diego Gas and Electric, Houston Natural Gas, Southern California Gas y Pacific Gas and Electric, entre otras, se han disputado la supremacía de lo que el presidente Bush definiera como "el mercado de exportación más grande de los productores de gas" estadounidenses, en la conferencia anual de la American Gas Association (AGA).

Según San Diego Gas and Electric (SDG\&E), las tasas de crecimiento de la demanda energética en la frontera norte mexicana "son astronómicas en comparación con las nuestras". Nada más la tasa de crecimiento de la demanda de gas natural en el norte de la Baja California "podría duplicar la del estado de California. De allí que nosotros estemos buscando exportar gas natural a esa zona, que es un excelente mercado para nuestra industria", señalo Thomas Page, director general de SDG\&B (El Financiero, 31 de octubre de 1991).

Rick Hillary, de Hillary \& Associates, consultora canadiense especializada en gas natural, ha afirmado que independientemente de su inclusión en el tratado, la situación de Pemex es tal que "todo acuerdo comercial es una potencial apertura del mercado para el gas de Texas, lo que, a su vez, abre más el área que pueden abastecer los productores de gas de Canada" (El Financiero, 31 de octubre de 1991:61).

La empresa canadiense ha advertido que la dependencia de combustibles pesados sigue generando crecientes problemas de contaminación en territorio mexicano, cuestión que estimula el interés en el uso de combustibles menos contaminantes, como el gas natural.

En opinión de Hillary \& Associates, "es absolutamente indispensable que México deje de consumir diesel y energéticos pesados, y comience a utilizar los de combustión menos contaminante. Sin embargo, los mexicanos no cuentan con gas suficiente, por lo que tendrán que recurrir a importaciones".

Respecto a ello, vale recordar la existencia del afiejo proyecto de la empresa texana Intercon Gas Incorporated, denominado México Natural Gas Pipeline Proyect (Transmexico-MexUS), según el cual se construiría "un gasoducto de alta presión de 36 pulgadas de diámetro a través de las 1,285 millas de la (parte mexicana) frontera", así como " 30 millas de lf́nea de 30 pulgadas de diámetro a través de la frontera estadounidense hasta un sistema de tuberías de cinco segmentos interconectados".

Ese sistema de ductos permitiría, por una parte, el desplazamiento del gas que se produce en el sur de Texas y en la parte estadounidense 
de la costa del golfo de México a los mercados de la costa del Pacífico norte (California, especialmente); por otra, permitiría que fluyera el "gas mexicano a mercados mexicanos" y fomentaría las inversiones bilaterales en el sector.

En el corto y mediano plazo la situación mexicana parecería favorecer a canadienses y estadounidenses por igual, sin embargo, en el largo plazo estaría más inclinado en favor de Canadá, pues "se espera que en unos siete años el estado de Texas se convierta en importador neto de gas natural", tendiendo la demanda a desplazarse a las gaseras de ese pais.

Por otra parte, según esta visión, los beneficios de la integración energética que plantea el tratado no se circunscriben a la cuestión del gas natural, pues "los mexicanos requieren cada vez más equipos petroleros" y Canadá es una importante fuente de esos recursos. Canadá cuenta con tecnología de punta en el aprovechamiento de crudos pesados, de los cuales tanto ese país como México cuentan con amplias reservas probadas, además de servicios de ingeniería y construcción de gasoductos y oleoductos.

De hecho - concluyen- "podemos visiumbrar un futuro en que productores canadienses y estadounidenses tendrán un papel protagónico al ayudar a México a desarrollar sus propios recursos petroleros y gasíferos" (El Financiero, 31 de octubre de 1991).

En mayo de 1992 se daba a conocer la intención de empresas gaseras norteamericanas en desarrollar una estrategia de reducciones en la producción para elevar precios. Ello parece revelar un rasgo de la vulnerabilidad asociada con la apertura hacia importaciones de gas en el norte del país.

Amparados en la regulación federal, Texas, Louisiana y Oklahoma han intentado aplicar un sistema de prorrateo a su producción, a fin de "evitar desperdicio y optimizar la recuperación del hidrocarburo".

El prorrateo es un mecanismo de manipulación de mercado que intenta controlar precios mediante restricciones a la producción de hasta $50 \%$. Al respecto, congresistas estadounidenses proponen una enmienda a la legislación que impida la manipulación de los precios de los combustibles (EI Financiero, 26 de mayo de 1992).

Además de someter a control federal a las comisiones regulatorias estatales, la enmienda propone someter a control a propietarios de gasoductos, distribuidores y consumidores que de algún modo pretendan afectar la producción para elevar los precios del gas.

"Si la producción de gas se reduce en $5 \%$, los precios del combustible podrían crecer fácilmente un $10 \%$, lo cual es magnifico para los productores, pero no para los consumidores", destacan analistas estadounidenses. 
Oklahoma, Louisiana y Texas representan cerca del $55 \%$ del total de la producción gasera estadounidense y el total de las importaciones mexicanas de gas natural.

El desinterés de las autoridades mexicanas en el sector petroquímico se ha manifestado de manera inobjetable. En junio de 1992, funcionarios que pidieron no ser identificados, seflalaron que "a Petroleos Mexicanos no le interesa participar como copropietario en proyectos petroquímicos, básicos o secundarios, dado que el programa de reorganización de la empresa tiene contemplada la total desincorporación del ramo". Ante esta apatía, proyectos estratégicos han sido interrumpidos y abandonados totalmente (El Financiero, 2 de junio de 1992a).

La decisión de desprenderse de la totalidad de la industria petroquímica -incluidas plantas ya construidas - ha sido tomada, y ello se vera tras un proceso de no más de un año. De este modo, antes de un par de afios Pemex habría concentrado todas sus actividades en la búsqueda y extracción de petróleo crudo, y con ello habrá reducido su función de abastecer las nuevas empresas privadas que cubran el mercado nacional.

\section{PERSPECTIVAS Y CONDICIONES DE INTEGRACIÓN ENER- GETICA MÍ́XICO-ESTADOS UNIDOS}

\section{Creciente participación privada en el sector energético}

Desde 1990 se anunciaba que el sector eléctrico habria de convertirse en "manzana de la discordia" entre empresarios privados, nacionales y extranjeros, una vez permitida la participación de particulares con más de una tercera parte de las inversiones totales requeridas para la construcción de centrales generadoras (El Financiero, 4 de diciembre de 1990).

El programa denominado "BT: Infraestructura para la generación de electricidad", ha buscado consolidar la perticipación del sector privado como "forma complementaria del ahorro en ciertas obras de infraestructura para $1991^{n}$.

En noviembre de 1991, ante un grupo de empresarios de 12 pafses europeos, el secretario de Energí, Minas e Industria Paraestatal, Fernando Hiriar, ratificaba la posibilidad para que empresas extranjeras participaran en sectores estratégicos y prioritarios en México, concretamente en la perforación de pozos petroleros, cogeneración de energía eléctrica, extracción y explotación de minerales (La Jornada, 10 de noviembre de 1991).

Habló de la participación en "perforación de yacimientos de hidrocarburos" por contrato de servicio, favoreciendo transferencias de tecnologia para modernizar la planta de transformación. Sobre electricidad, indico 
avances en la autogeneración y cogeneración de electricidad en "aquellas empresas que por sus caracteristicas pueden hacerlo", solucionando, en parte, la demanda creciente que tiene México.

En diciembre de 1991, el subsecretario de Inversiones Extranjeras de la Secretaria de Comercio y Fomento Industrial, Fernando Sánchez Ugarte, sefialaba que México está abierto a la inversión foránea en áreas "no tradicionales", como son la construcción de plantas termoeléctricas, financiamiento para creación de complejos petroquímicos, el campo y hasta los ferrocarriles, en "donde hay oportunidad abierta para los inversionistas, pues todavía tenemos la privatización de Ferrocarriles Nacionales" (La Jornada, 4 de diciembre de 1991).

Al liberalizarse muchas actividades económicas del pais, se generan oportunidades de inversión para empresarios extranjeros, sobre todo en rubros donde tradicionalmente no se permitía su participación, como Teléfonos de México, Comisión Federal de Electricidad, Petróleos Mexicanos y Ferrocarriles Nacionales.

El esquema de construcción de plantas con capital extranjero operará también en Comisión Federal de Electricidad, bajo el mismo sistema de financiamiento de la construcción de plantas termoeléctricas. Estas plantas-paquete funcionarán mediante arrendamiento financiero.

La construcción de una termoeléctrica conlleva una inversión de entre 120 y 150 millones de dólares. Empresarios extranjeros la desarrollan y financian; luego la alquilan a Comisión Federal de Electricidad y, por medio de arrendamiento financiero, termina siendo propiedad de Comisión Federal de Electricidad.

El funcionario consideró no prever reformas a la Ley de Inversiones Extranjeras; sin embargo, no descartó la posibilidad de modificaciones si las circunstancias así lo requieren. La desregulación y la privatización emprendidas han dejado "un ambiente muy favorable a la inversión extranjera" y se seguirá fomentando la inversión en áreas tradicionales, como el turismo, la industria maquiladora y el sector automotriz ( $\mathrm{La}$ Jornada, 4 de diciembre de 1991).

Dentro del paquete de iniciativas de ley para profundizar la participación privada en la economía, se incluyo, en mayo del presente año, un anteproyecto para reglamentar generación y cogeneración de energla eléctrica por parte de nacionales y extranjeros. Con ello se legaliza la presencia de plantas termoeléctricas en maquiladoras fronterizas, algunas de las cuales llegan a vender sus excedentes (La Jornada, 12 de mayo de 1992).

Se legaliza la construcción, por parte de cuando menos tres empresas nacionales, Cementos Mexicanos, Grupo Sidek y Grupo Autrey, de plantas termoeléctricas en diversas partes del país. La primera, para dar servicio a 
su red de cementeras y concreteras; la segunda, para ofrecer energia a corredores industriales instalados a la vera de algunas ciudades de la península de Baja California; y la tercera, para alimentar la planta Monclova de Altos Homos de México. Se formaliza uno de los acuerdos a que arrib6 la mesa de negociación número 6: "Otras industrias", del Tratado de Libre Comercio, en su subcapítulo, "Energia".

De acuerdo con la óptica gubernamental, el que particulares nacionales o extranjeros generen su propia electricidad y vendan excedentes, no lesiona restricciones constitucionales, ni implica una privatización de la Comision Federal de Electricidad, dado que ésta administrará las plantas que se creen e intermediará las ventas que se realicen.

Mateo Treviño, director del programa de ahorro de energía del sector eléctrico, declaraba en mayo de 1992, que "desde hace más de una década ya era factible para el sector privado participar en la construcción de plantas de generación eléctrica para el autoabastecimiento"; sin embargo, las condiciones no favorecieron este tipo de proyectos. Grandes reservas permitian que las tarifas eléctricas fueran baratas, no haciendo atractiva la inversión privada en plantas eléctricas. Sin embargo, es posible que pronto se concreten alrededor de 20 proyectos, entre los que destacan los de Cydsa, Pipsa, Celulosa Chihuahua y Crisoba (El Financiero, 12 de mayo de 1992).

El sector privado cuenta con capacidad instalada nacional de 2,733 megawats, con 178 plantas en 13 ramas diferentes, que equivale a $10 \%$ de la capacidad instalada del sector eléctrico. La industria siderúrgica encabeza la lista generando 460 megawatts, sigue la química, con 429 megawatts y después la cementera, alimenticia, cartón y papel, cervecera, textil y metalúrgica, entre otras.

La apertura ha generado espacios importantes para el surgimiento de actividades altamente rentables hacia empresas líderes del sector privado. Así un nutrido grupo de empresas líderes del sector, decididas a expandir sus operaciones y aprovechar la reorganización de la industria petrolera mexicana, ha negociado, presionado y cabildeado a fin de obtener la concesión para la construcción y operación de la primer planta de éter metilterbutilico (MTBE) del país (El Financiero, 2 de junio de 1992).

Los candados presupuestarios, la carencia de tecnología propia para la producción de MTBE, así como su creciente demanda y, sobre todo, el proceso de reorganización de la propia empresa, determinaron la decisión gubemamental para recurrir al capital foráneo. Para ello hubo que reclasificar el petroquímico - hasta entonces considerado básico-, lo que se hizo oficialmente a partir del 7 de junio de 1991, cuando se publicó el decreto que lo convertía en petroquímico secundario. 
Ha sido notable el esfuerzo por fundamentar la decisión de reestructurar la paraestatal mexicana de petroleo, como consta en un documento interno de Petróleos Mexicanos, fechado en junio, en donde se seffala que: "la reestructuración ... pretende hacer de la empresa un instrumento ágil y de apoyo que coadyuve al logro de los nuevos objetivos nacionales".

La nueva compañía opera bajo cinco líneas integradas - producción primaria, transformación industrial, petroquímica y gas, comercialización y administrativa-, a las que se les delega mayor autonomia de gestión. El logro de la excelencia productiva y de competitividad serán los criterios fundamentales para las actividades de la institución en los próximos meses (El Financiero, 10 de junio de 1992).

El texto asienta que a nivel macroeconómico, Pemex continuará aportando alrededor de un tercio de los ingresos federales, por ser fuente de divisas que permite cubrir servicio de la deuda externa sin causar desequilibrios macroeconómicos. En cuanto a petroquímica y gas, el documento apunta que el nuevo perfil de eficiencia y productividad servirá de impulso a esta actividad, en cuanto a transformarla para abastecer competitivamente a la industria nacional y hacerla fuente de nuevas exportaciones.

\section{Infraestructura y financiamiento en el norte de México}

Exportaciones eléctricas contratadas con Comisión Federal de Electricidad en la frontera norte del pars, resultado de un proceso incipiente aunque significativo de integración energética bilateral, apenas unos años después, han manifestado sintomas de vulnerabilidad.

Dos de las principales empresas del sector eléctrico estadounidense que compran energía eléctrica mexicana anunciaban, en mayo de 1991, su intención de cancelar los contratos de compra-venta con Comisión Federal de Electricidad para sustituirlos por algún mecanismo que no les cueste dólares.

Según Programas de Recursos 1991-2000 de San Diego Gas \& Electric Company (SDG\&E) y de Southern California Edison Company (SCE), las importaciones de energía provenientes de territorio mexicano serían sólo temporales, dados los problemas que afronta el sector en Estados Unidos y se espera sean resueltos a mediano plazo (El Financiero, 28 de mayo de 1991).

Actualmente existen contratos para la venta de 200 megawatts de capacidad firme de la CFE a la Western Systems Coordinating Council (WSCC). Las empresas SDG\&E y SCE tienen contatos de compra con CFE en el área de Baja California por $150 \mathrm{MW}$ y $70 \mathrm{MW}$ hasta 1995. Forman parte de un "programa de ventas anticipadas" con que las autoridades pudieron 
allegarse recursos para continuar los programas de expansión del sector eléctrico, por un monto aproximado a los 400 millones de dólares durante cuatro años (El Financiero, 28 de mayo de 1991).

No obstante lo declarado antes por las empresas, autoridades estadounidenses y mexicanas han realizado constantes reuniones de evaluación para determinar mecanismos con los que puedan prolongarse las relaciones comerciales de energía eléctrica.

En este sentido, un estudio elaborado en marzo de 1991 conjuntamente por el departamento de Energía de Estados Unidos, la Secretaría de Energia, Minas e Industria Paraestatal, la Comisión Federal de Electricidad y compañías eléctricas del sur de Estados Unidos, seffala que:

la única oportunidad de lograr ventas o compras de capacidad firme a mediados de los noventa sólo será posible si se incorporan nuevas plantas generadoras tanto en las áreas de wsoc como de CFE [...] Si no se construyen nuevas plantas, ni CFB ni wSCC tendrán posibilidades de vender capacidad firme de energía, sobre todo en verano, y simultáneamente mantener los márgenes adecuados de reserva para el resto de la década.

De acuerdo con el Programa de Obras e Inversiones del Sector Eléctrico 1990-2000, Baja Califomia presenta, a partir de 1991 y hasta el término del sexenio, un déficit de energía entre reserva programada y reserva requerida que crece de 34 a 73 MW entre 1991-1994. Ante esta posibilidad ambos gobiernos estudiaron la conveniencia de un proyecto para interconectar los sistemas eléctricos de México y Estados Unidos, con el fin de intercambiar energía eléctrica a bajos costos.

El mencionado proyecto - debatido en la mesa de negociación correspondiente del TLC - tiene previsto "instalar un corredor de plantas generadoras en territorio mexicano financiadas con capital estadounidense". Ello haria posible un suministro confiable y seguro de energía eléctrica hacia ambas regiones. En el caso de México, el mecanismo garantiza recursos para continuar con la expansión del sistema y poder suministrar la energía requerida por la zona fronteriza,

Para Estados Unidos el mecanismo significa trasladar los costos de construcción de plantas generadoras a México, considerando que en suelo mexicano resulta más barato generar energía para atender parte de la demanda del mercado sur estadounidense. Se traslada también el impacto ambiental, pues la legislación -y su cumplimiento- en Estados Unidos en materia de construcción de plantas y generación de energía eléctrica es mucho más rígida que en México (El Financiero, 28 de mayo de 1991). 
En junio de 1991 un grupo de funcionarios, economistas y académicos declaran que "los mayores obstáculos a la expansión maquiladora y a la eventual integración económica norteamericana, son la falta de infraestructura y la deficiencia de los servicios públicos en México", por lo que tan importante como las negociaciones comerciales es la búsqueda de fórmulas de financiamiento para resolver el "déficit infraestructural" (El Financiero, 4 de junio de 1991).

La integración física de los sistemas eléctricos de Estados Unidos y México, el cobro de un gravamen a la industria maquiladora y la creación de un nuevo banco de fomento norteamericano, son algunas propuestas que se manejaron en el marco de las negociaciones entre Estados Unidos, México y Canadá.

En estudio elaborado en 1991 por el Departamento de Energía de Estados Unidos, se planteó el establecimiento de "interconexiones permanentes" de la red eléctrica de empresas privadas estadounidenses, como la texana Electric Reliability Council con Comisión Federal de Electricidad.

Otras propuestas abarcan la participación conjunta de CFE y companías estadounidenses en la construcción de nuevas unidades generadoras y la exportación de electricidad estadounidense a "precios competitivos" para qubrir el déficit en la demanda de las ciudades fronterizas mexicanas donde se proyecta una significativa expansión de la maquila.

Así mismo, advierte cómo "a medida que se intensifique el flujo de bienes y gente en la zona fronteriza, el mejoramiento de carreteras y puentes internacionales, viviendas y servicios públicos, será imperativo" en el lado mexicano de la frontera. El estudio describe lúcidamente el atraso de la infraestructura del país, aunque no ofreció alternativas de financiamiento, ni estimó el monto inicial de inversión.

George Baker, de la Universidad de Berkeley, ha observado que en realidad no existe un análisis que cuantifique el costo del financiamiento de la infraestructura en el norte del país, pero añade que con base en estimaciones de la embajada de Estados Unidos para 1983, la inversión se ubicaba en 6 mil millones de dólares, por lo que es posible que los requerimientos hayan ascendido a 20 mil millones de dólares (El Financiero, 4 de junio de 1991).

La necesidad de modemizar la infraestructura y los servicios públicos en México, ha llevado a otros especialistas a proponer la creación de una nueva institución financiera. Albert Fishlow, Sherman Robinson y Raúl Hinojosa-Ojeda, economistas de la Universidad de Califomia en Berkeley, han planteado lafundación de un Banco de Fomento Regional Norteamericano y Fondo de Ajustes para asistir a México principalmente y, en menor grado, a regiones de Estados Unidos y Canadá que resulten afectadas con el TLC. 
El propuesto banco debe concentrarse en financiar proyectos de infraestructura para el "mejoramiento del intercambio comercial", como son la construcción de carreteras, puentes, puertos, ferrocarriles, aduanas, así como en el "desarrollo de la integración de las fronteras" (El Financiero, 4 de junio de 1991).

Por su parte, la Secretaría de Energía, Minas y Recursos del gobierno de Canadá ha propuesto, desde 1991, la integración de la industria gasera de los tres países que participan en el TLC (El Financiero, 10 de diciembre de 1991).

El mayor obstáculo al aumento de las importaciones de gas que tiene México - sostiene Administración Internacional Energética-es la carencia de gasoductos e infraestructura en territorio mexicano. Buena parte de la industria mexicana está cerca de la frontera y de los gasoductos estadounidenses, por lo que se requeriría la construcción de una cantidad moderada para "conectar el suministro del sur estadounidense a los nuevos mercados mexicanos". Al mismo tiempo, "en la eventualidad de que sea grande la demanda mexicana de gas, abastecedores estadounidenses podrian traer gas del Norte, lo que abriría oportunidades a la industria gasera canadiense".

Elevar las exportaciones de gas a México demanda una inmediata ampliación de la red de gasoductos, Oil and Gas Journal 1991 Data Book, menciona varias empresas encargadas de las obras en marcha o bajo propuesta, entre las que destaca el Proyecto de Energía Trinacional a cargo de la Corporación Nova de Alberta (Canadá), las estadounidenses Community Energy Alternatives, Intercon Gas y dos empresas mexicanas.

Desde 1981, el servicio geológico del gobierno estadounidense, estimó en 180 billones de pies cúbicos los recursos convencionales de gas mexicano, suma que se considera aproximadamente igual a las estimaciones de reservas no descubiertas en Canada. En riqueza gasera, México goza de enormes "ventajas geológicas comparativas" en relación con Canadá y Estados Unidos. El rendimiento del pozo promedio mexicano es de 555 barriles de petróleo por día (bpd), en comparación a 39 del canadiense y 12 del estadounidense.

Según la fuente,

dada la ubicación estratégica de las reservas de gas mexicano, contiguo al mercado de gas y la infraestructura de gasoductos norteamericanos, puede decirse que México es un "gigante dormido" respecto al mercado norteamericano y una fuente de largo plazo de "suministro zaguero" (El Financiero, 10 de diciembre de 1991). 
México tiene el potencial de convertirse en "jugador decisivo" en el mercado estadounidense, ya sea como importador o exportador. Lo anterior dependerá de la disponibilidad de capitales, la demanda interna de gas mexicano; política de precios en México y precio mundial del petróleo (El Financiero, 10 de diciembre de 1991).

\section{Proyectos transfronterizos de integración energética}

Desde principios de 1991, Comisión Federal de Electricidad reveló que las plantas generadoras de energía eléctrica instaladas en la franja fronteriza serían interconectadas al sistema eléctrico de Estados Unidos. Se indicaba el avance en las negociaciones faltando por resolver ciertos aspectos técnicos. El programa incluyó centrales de cuatro entidades federativas: Tamaulipas, Coahuila, Chihuahua y Baja California, que en su conjunto exportarán 1,920 gigavatios-hora $(\mathrm{GVH})$ anuales o más $(E l$ Financiero, 29 de enero de 1991).

México se compromete a interconectarse al sistema eléctrico estadounidense a cambio de recursos que recibió por ventas anticipadas de energfa eléctrica, calculados en $\mathbf{4 5 0}$ millones de dólares. Con ese capital tendrá que concluir obras y trabajos de plantas instaladas en la frontera norte y destinar parte de la energia que produzcan al mercado estadounidense.

México mantiene convenios de venta e intercambio de energía con empresas de California y Texas. Con base en estos convenios, la venta de energía producida en México llegó a 1,932 gigavatios-hora en 1989 y a 1,927 en 1990.

Por otro lado, las elevadas tasas de demanda de gas natural en México, sobre todo en su región fronteriza con Estados Unidos, comenzaron desde hace casi dos años a mover la competencia de las gaseras estadounidenses, preparándose para atender al mercado mexicano de ese energético ( $E l$ Financiero, 29 de enero de 1991).

El departamento de energía de Estados Unidos y CFE estudiaron incluso la posibilidad de intercambiar petróleo mexicano por electricidad, proveniente ésta de cuando menos 29 empresas privadas y mixtas instaladas en la frontera sur de ese país (El Financiero, 6 de junio de 1991).

A cambio de electricidad, proveniente de las empresas estadounidenses que integran la Electric Reliability Council of Texas y Western Systems Coordinating Council (ERCOT y wSCC respectivamente), el gobierno mexicano estaría dispuesto a suministrar crudo para las plantas generadoras del sur de Estados Unidos.

Sin embargo, especialistas de ambos países argumentaron sobre las escasas posibilidades de intercambio de combustibles por energía eléc- 
trica, ya que, al menos en Estados Unidos, el suministro de combustible y las empresas generadoras no pertenecen a una misma corporación. Sin embargo, sostienen que "en el futuro ésta puede ser un área para análisis adicionales por alguna de las partes interesadas en explorar las posibilidades de incrementar el intercambio de electricidad entre Estados Unidos y México" (El Financiero, 6 de junio de 1991).

Algunas empresas norteamericanas interesadas en ese intercambio, participantes en la elaboración del estudio, fueron Public Service Company of New Mexico, El Paso Electric Company, Citizen's Utilities Company, Arizona Electric Power Cooperative, Tucson Electric Power Company, Salt River Project, Arizona Public Service Company, Southern California Edison Company, San Diego Gas and Electric e Imperial Irrigation District.

Como puede verse, las condiciones para incrementar el intercambio de electricidad entre México y Estados Unidos han sido evaluadas. Las autoridades correspondientes han tomado una serie de decisiones que buscan lograr beneficios económicos, aunque en la negociación parecen haber cedido espacios en áreas antes defendidas con determinación ( $E I$ Financiero, 6 de junio de 1991).

El estudio "Mexican Sectors: Potential Impacts on The North American Market", elaborado por una consultoría internacional privada, indica que uno de los renglones para inversión libre de aprobación gubernamental que más interesa a corporaciones de Estados Unidos y Canadá es el energético y éste permanece altamente protegido al analizar el impacto potencial de algunos sectores una vez integrada el área comercial norteamericana (El Financiero, 15 de enero de 1992).

Corporaciones como Mobil, Enron, Exxon, Ammoco, entre otras, no sólo recurrieron a sus gobiemos para presionar la apertura del sector energético mexicano; también negociaron con la representante de Petróleos Mexicanos en el exterior, es decir, Petróleos Mexicanos Intemacional.

Según el texto, PMI ha buscado contratos de largo plazo en el exterior que permitan reactivar las operaciones petroleras, aunque esto no signifique necesariamente una "entrega del petróleo a manos extranjeras".

La Comisión Reguladora de Energía del gobierno federal de Estados Unidos (FERC) aprobó, desde principios de 1992, un reglamento que restructura sustancialmente los servicios interestatales de distribución de gas natural por medio de oleoductos. El reglamento fue diseflado para asegurar que las companías proporcionen un servicio de transporte igual en calidad para toda la oferta de gas, ya sea que el cliente lo compre al distribuidor o a cualquier otro abastecedor.

La reglamentación surge a la par que analistas del mercado de energéticos consideran que Estados Unídos es capaz de expandir su producción 
de gas natural durante un largo periodo, y con costos competitivos respecto de otros energéticos (El Financiero, 10 de abril de 1992).

Según el National Petroleum Council - grupo de ejecutivos y consejeros del secretario de energfa de E.E.U.U.-, el mayor potencial de crecimiento en el mercado del gas descansa en la generación de energía eléctrica. Sin embargo, advierte que la industria debe cancelar percepciones equivocadas respecto a confiabilidad, entrega y futuros incrementos de precios, a efecto de capturar una gran parte de este mercado.

El creciente uso de gas requerirá mayor capacidad de oleoductos; todos los segmentos de la industria deberán mejorar su calidad de servicio, particularmente en lo relativo a mercadeo, señaló el NPC y advirtió que conforme se expanda la industria las regulaciones habrán de variar $(E l$ Financiero, 10 de abril de 1992).

Representantes de Pemex, manifestaron públicamente en junio de 1992 la decisión de ceder la comercialización de gas natural de la parte norte del territorio a empresas norteamericanas. "Petróleos Mexicanos no tiene la infraestructura necesaria para desplazar el combustible al norte del país, por lo cual el abasto de esa zona se hará con importaciones procedentes de Estados Unidos", indicaba Pedro Gómez Flores, subdirector de Petroquímica Básica y Gas Natural de Petróleos Mexicanos Internacional (El Financiero, 23 de junio de 1992).

Los principales consumidores domésticos del combustible son Pemex, que lo utiliza como insumo para la producción de petroquímicos básicos y Comisión Federal de Electricidad en sus procesos de generación de energía eléctrica, con quien negocia actualmente nuevos contratos de suministro.

Destacó que "las crecientes regulaciones ambientales, la racionalidad en el uso de la energía y la economía en el gasto energético son factores que impulsan el interés por el gas natural".

Durante 1991 México incrementó más de 390\% sus importaciones de gas natural provenientes de 25 companías de Estados Unidos, siendo que hace apenas unos años fue exportador neto del combustible hacia el vecino país del norte. Hay proyectos para que empresas estadounidenses construyan más gasoductos en la zona norte del territorio mexicano asegurando el suministro del hidrocarburo.

Según Oil \& Gas.Journal, la industria maquiladora y algunos proyectos de energía eléctrica "seguirán empujando la demanda de este combustible en los estados mexicanos fronterizos. Pemex no tiene considerado intensificar sus trabajos de exploración de este recurso, pues además de que el combustible lo compra en el mercado spot a más bajos precios, el gobierno mexicano puede minimizar de esta manera la inversión en industria petrolera" (La Jornada, 12 de mayo de 1992b). 
La publicación menciona que a Pemex le resultará más rentable extender sus ductos hasta la zona fronteriza para conectarlos con los de las empresas extranjeras. El editor del Gulf Coast News, A.D. Koen, afirma que las perspectivas de una fuerte demanda y crecimiento continuo para las importaciones de gas natural a México mantienen a la expectativa a productores y constructores de gasoductos.

En ese contexto, funcionarios mexicanos esperan que la demanda de energía eléctrica se incremente 5\% hacia el ano 2000. "Una economía mexicana sana y la conclusión del Tratado de Libre Comercio, se espera que alienten la expansión de la capacidad generadora de energía eléctrica y aumente la actividad industrial de los estados norteños de México".

La Oficina de Información de la Energía del Departamento de Energía estadounidense ha previsto que la producción de gas en su país alcanzará su máximo nivel en la primera década del siglo XXI. En algún momento, Estados Unidos podría "volver a ser un importador neto del gas mexicano, con volúmenes que llegarian en el afio 2010 a sus más altos niveles".

Sin embargo, la predicción dependerá de la tasa a la que se incremente la demanda de gas de México. "También México tendrá que poner de nuevo énfasis en el desarrollo de sus reservas potenciales de gas, y hasta ahora no hay indicios de esos planes", sefiala la dependencia de Estados Unidos.

La única fuente capaz de competir con el gas estadounidense y canadiense en los mercados del norte de México está asociada con el gas de los campos petroleros en el centro y sur de México. Un estudio de Oil \& Gas Journal menciona que, por recortes presupuestarios, la companifia petrolera del estado parece incapaz de incrementar sus exploraciones y gastos de producción para el combustible, menos aún para montar un programa de exploración y producción de gas.

Sin la inyección de capital privado, Pemex parece incapaz de financiar la construcción de gasoductos de gran diámetro, necesarios para mover grandes volúmenes de gas a los mercados del norte de México y Estados Unidos.

De acuerdo con la Oficina de Programas de Combustible, en 1991 cuatro companfías estadounidenses tenían puntos de exportación para los gasoductos con México: tres en Texas y uno en Arizona. Asf, menciona que entregas de la Texas Eastern Transmission Corp. (Tetco) en su gasoducto de exportación de McAllen a Reynosa, Tamaulipas, subieron a finales de 1991 y constituyen el volumen más grande de gas estadounidense que entra a México.

En noviembre de 1991,

El Paso Natural Gas Co. empezó a mandar gas a Ciudad Juárez, Chihuahua, por medio de Gas Interstate (WGI), que está en Austin; 
el gas se usa para una de las dos unidades de la planta generadora en Samalayuca, Chihuahua, operada por Comision Federal de Electricidad (La Jornada, 12 de mayo de 1992).

También en 1991 El Paso exportó gas a México por un gasoducto que entregaba el combustible a la frontera cerca de Naco, Arizona. KLA entrega y alimenta la operación de refinamiento del cobre, cerca de Cananea, y una planta ensambladora de la Ford Motor Company que está al sur de Hermosillo, ambas en el estado de Sonora (La Jornada, 12 de mayo de 1992).

Las gaseras Transaco de Texas y Coastal de Carolina del Norte participan en la subasta de un contrato para construir una planta eléctrica en Ciudad Juárez, Chihuahua. Voceros de ambas empresas han señalado que sus filiales Transaco Energy Ventures de Houston y Duke Energy de Charlotte formaron una sociedad para participar en la subasta del proyecto Samalayuca de la Comisión Federal de Electricidad. La planta ha de generar 700 megawatts, con capacidad para satisfacer la demanda de 2.5 millones de personas en esa zona fronteriza (El Economista, 22 de julio de 1992b).

Valero Energy Corporation terminó trabajos de construcción de la interconexión que une su sistema de distribución de gas natural en McAllen con los objetivos industriales de Reynosa, en Tamaulipas y desde agosto de 1992 sus ductos introducen a México un promedio diario de 125 millones de pies cúbicos de gas natural, aunque se espera que a fines de año el volumen se incremente a 200 millones (El Financiero, 4 de agosto de 1992b).

Con esas instalaciones, Valero se convierte en la cuarta empresa estadounidense que extiende sus gasoductos hasta territorio nacional. Las otras son Texas Eastern Transmission, Western Gas Interstate y El Paso Natural Gas, cuyos sistemas de suministro cubren prácticamente todo el norte mexicano.

Megaproyecto de infraestructura en la era del TLC: la central gasoeléctrica de Tijuana, Baja California

La central eléctrica más grande de México será construida en Tijuana con una inversión cercana a los mil millones de dólares, de acuerdo con un proyecto de seis empresas estadounidenses, encabezado por la Constructora Bechtel y la Petrolera Pan Coastal Guard (El Financiero, 26 de junio de 1991a).

En junio de 1991, las empresas declaran que la central eléctrica surtiría de 500 megawatts a México y Estados Unidos, desalinizando 100 millones de galones de agua diarios para su venta al estado de California. 
La companía constructora californiana Bechtel, la petrolera texana Coastal, los departamentos de agua de San Diego y Los Ángeles y la compañía eléctrica Edison invirtieron 600 mil dólares en un estudio de factibilidad concluido a fines de julio del ano pasado (El Financiero, 26 de junio de 1991b).

La ubicación del lado mexicano de la planta fue reconocida como ventajosa por Tom Bradley, alcalde de Los Ángeles, al seffalar que el precio del terreno frente a la costa es mucho más barato del lado mexicano, En el acto participaron, el cónsul de México en Los Ángeles, Miguel Ángel Pescador y el gobernador de Baja California, Emesto Ruffo Appel, quien de acuerdo con un comunicado de prensa "avaló públicamente el proyecto".

El reporte de factibilidad, de acuerdo con Allan Bradley, vicepresidente ejecutivo de Coastal, permitirá precisar los montos de inversión que dijo "esperamos se financien con fondos privados".

Por su capacidad generadora, la planta sería la central eléctrica más grande e importante de México, operando con gas natural exportado desde los Estados Unidos del orden de 25 millones de pies cúbicos al día.

La opción para el transporte del gas por la que se inclinó el estudio implica que la compañía El Paso Natural Gas lleve el energético hasta Yuma en Arizona y de ahi cruce la frontera, llevándose por territorio mexicano desde Mexicali hasta Tijuana.

La actividad de suministro eléctrico podría llevarse a cabo únicamente por un inversionista privado, nacional o extranjero, después de obtener una resolución aprobatoria y su consecuente autorización por parte de la Secretaría de Comercio y Fomento Industrial (Secofi), bajo la modalidad de fideicomiso con fundamento en el artículo 23 del reglamento de mayo de 1989, y una vez satisfechos los requisitos que ese propio reglamento le impusiera.

Ejecutivos de las firmas confirmaron haber estado en contacto con Comisión Federal de Electricidad, Pemex, Secretaria de Desarrollo Urbano y Ecologia (Sedue) y Secofi, entre otras. "Sus comentarios iniciales son alentadores, pues están de acuerdo en que el proyecto beneficiaría a Baja California", mencionó March (El Financiero, 26 de junio de 1991b),

Varios meses después, el residente general de obras de Comisión Federal de Electricidad, Francisco Javier Garibay, confirmaba que con el fin de atender la creciente demanda de suministro eléctrico en esta región del país, el gobierno federal con apoyo de inversionistas privados construiría una nueva central termoeléctrica en la zona, iniciando su operación comercial hacia fines de 1993 o principios de 1994 (La Jornada, 18 de diciembre de 1991). 
Además de los intercambios de electricidad con Estados Unidos se programa aumentar los excedentes de electricidad hacia ese pais. Eventualmente, podría construirse una central nucleoeléctrica, aún cuando el proyecto seria de más largo plazo. Sin embargo ya se reúnen funcionarios de ambos países para analizar tal posibilidad.

En 1992, Comisión Federal de Electricidad lanza la convocatoria a la iniciativa privada nacional y extranjera para la construcción de las cuatro plantas generadoras de electricidad en la zona norte del país. La intención era que en 1994 entraran en operación las plantas como unidades de "ciclo combinado" pudiendo consumir, ya sea combustóleo o gas. Las plantas - a instalarse en Rosarito y Tijuana-podrán generar un promedio de 700 megawatts, además de contar con tecnología avanzada en la materia, contemplando que a mediano plazo sólo operen con gas (El Financiero, 18 de diciembre de 1991).

En agosto de 1992 - casi un año después que lo informaron las empresas constructoras - la Dirección de Promoción Económica del Gobiemo del estado de Baja California anunció que la planta gasoeléctrica más grande del país será construida en Tijuana. Para su instalación se tiene contemplada una inversión de mil millones de dólares y en el proyecto participarán seis empresas estadounidenses (La Crónica, 13 de agosto de 1992).

\section{HACIA UNA DISCUSIÓN REGIONAL DEL DESARROLLO DEL SECTOR ENERGÉTICO}

Las negociaciones comerciales recientes - tanto dentro como fuera del tratado- revelan el carácter nodal del tratamiento correspondiente al sector energético. Posiciones de los agentes económicos y políticos en los tres paises convergen hacia una mayor intensificación de los intercambios y la participación directa en la producción y distribución de la energía.

Las presiones hacia una mayor apertura del sector en México resultan coincidentes con la escasez de recurso interno destinado a la inversión requerida para incrementar la capacidad instalada, fundamentalmente en materia de generación de energía eléctrica y producción de gas natural.

En términos territoriales, el proceso anterior se traduce en un importante incremento de la infraestructura e instalaciones para el abasto energético de las regiones norteñas mexicanas, con la característica de impulsar concomitantemente el crecimiento de la capacidad firme de generación eléctrica orientada a la exportación. Considerando la proximidad con la frontera estadounidense, particularmente la de algunos centros de población, es previsible una mayor atención de las preocupaciones ambientales y con ello, la orientación de la producción hacia el uso de combustibles 
menos contaminantes, entre los que destaca la utilización del gas natural, En esta materia, a mediano plazo se contempla la posible trilateralidad del proceso integrador, dadas las limitaciones que ofrece la oferta norteamericana respecto a las necesidades de abastecimiento que surgen en el norte de México.

La dinámica de los actuales procesos de integración impone importantes restricciones desde la óptica de una planeación nacional de estrategias de desarrollo. Su naturaleza y condiciones no parecen descartar, en cambio, la posibilidad de optimizar mecanismos de regulación, tanto sobre la industrialización y actividad económica general, como de las modalidades correspondientes al sector energético, en particular.

Debe seffalarse, sin embargo, la ausencia de un examen detenido y socialmente participativo tanto de los elementos que fundamentan decisiones implícitas en la comercialización como de la formulación de programas sectoriales por sus repercusiones sociales y territoriales.

En este sentido, resulta conveniente impulsar una evaluación del esfuerzo global de reestructuración de la actividad exportadora a la luz de los beneficios y costos asociados, más allá de su contribución a la generación de divisas y del surgimiento de nuevas modalidades de infraestructura y capacidad productiva a mediano y largo plazos.

El contexto más amplio de la relación externa no ha sido del todo favorable. La debilidad comercial ha avanzado y los términos de intercambio se han deteriorado. Aun cuando la economía mostrara crecimientos positivos, se han originado importantes limitaciones externas. Conforme han crecido precio y volumen de importaciones, las relaciones de intercambio se han deteriorado. Un mayor grado de diversificación exportadora resulta razonable aunque quizá más si se sustenta en actividades no-intensivas en importaciones (El Financiero, 28 de mayo de 1992).

Un aspecto adicional a considerar - desde una óptica urbano- regional-sería la ponderación de las ventajas o beneficios para las entidades y centros de población involucrados materialmente en la intensificación del intercambio comercial. Reivindicar la función clave de industrias de base exportadora como sectores que propicien una dinamización cuyos efectos resulten menos adversos al estilo de desarrollo, especialmente, de sus condiciones sociales e infraestructura.

Ello podría conducir a una reestructuración organizacional de mayor contenido regional de las empresas estratégicas en México. Analizando debidamente sus efectos económicos, sociales y ambientales, tanto como condiciones óptimas de localización, financiamiento y desartollo productivo. 


\section{BIBLIOGRAFÍA}

CAMERON Maxwell A. 1991. "North American Free Trade, Public Goods and Asymetrical Bargaining: the Strategic Choices for Canada". Frontera Norte, vol. 3, no. 6, julio-diciembre.

CARRILLO Viveros, Jorge. 1989." "Calidad con consenso en las maquiladoras. ¿Asociación factible?". Frontera Norte, vol. 1, no. 2, Tijuana, El Colegio de la Frontera Norte.

GONZÁLEZ Arechiga, Bernardo y José Carlos Ramírez. 1989. "Los efectos de la competencia internacional en el funcionamiento de la industria maquiladora de exportación en México". Frontera Norte, vol, 1, no. 2, Tijuana, El Colegio de la Frontera Norte.

GUTIÉRREZ, Roberto. 1982. "El sector energético de México". Miguel Wionczeck, et al. Posibilidades y limitaciones de la poltitica energética mexicana. El Colegio de México.

GUTIÉRREZ, Roberto y Adriana Ortiz. 1982. "Desarrollo y planeación del subsector de hidrocarburos". Miguel Wionczeck, et al. Posibilidades y limitaciones de la polticica energética mexicana, El Colegio de México.

GUTIÉRREZ, Roberto. 1991. "Desarrollo y consolidación de la industria petroquímica mexicana", Comercio Exterior, vol. 41, no. 4, México, abril de 1991.

PASTOR, Robert y Jorge G. Castafieda. 1989. Limites en la Amistad. México-Estados Unidos, Editorial Joaquín Mortiz/Planeta, México.

RANFLA González, Arturo y Ana María Avilés Muffoz. 1988. "La reciente inserción internacional de la industria mexicana y su impacto regional". Estudios Fronterizos, no.15-16, Instituto de Investigaciones Sociales, UABC, Mexicali.

SORDO, Ana María. 1982. "Exploración y Explotación", en Miguel Wionczeck, et al. Posibilidades y limitaciones de la politica energética mexicana. El Colegio de México.

STEWART Gordon T. 1991. "Three lessons for México from CanadianAmerican relations". Frontera Norte, vol. 3. no. 6, julio-diciembre.

SUÁREZ Villa L. 1984. "Manufacturing process cycle in the industrialization of the United States Borderlands". The Annuals of Regional Science. Vol. 18, no 1, Marzo.

VERNON, Raymond. 1966. "International investment and intemational trade in the product cycle" Quarterly Journal of Economics, Vol. 80. 
PERSPBCTIVAS DE INTEGRACION ENERGETITCA

\section{Periódicos y revistas}

\section{La crónica}

13 de agosto de 1992. "Construirán hidroeléctrica más grande del país en Tijuana."

\section{El economista}

28 de junio de 1991. "Aumentar representantes obreros en la unidad negociadora del TLC, pide el CT. Reafirma Serra que no se negociarán petróleo, ferrocarriles, telégrafos, electricidad y petroquímica básica."

22 de julio de 1992a. "Tratado de Libre Comercio".

22 de julio de 1992b. "Negocios México-EU."

13 de agosto de 1992. "El tratado, favorable a los intereses de México: Serra Puche."

\section{La Jornada}

10 de noviembre de 1991. "Posible, la participación extranjera en áreas estratégicas."

4 de diciembre de 1991. "México está abierto a la inversión extranjera: Secofi, Petróleo, campo, bolsa y electricidad, entre las áreas que se mencionan,"

18 de diciembre de 1991. "Construirán una termoeléctrica en BC con apoyo privado, Iniciaría su operación comercial a fines de 1993 o a principios de 1994."

abril de 1992. "En turno la Comisión Federal de Electricidad."

12 de mayo de 1992a. "Y se hizo la luz... privada."

12 de mayo de 1992 b. "México aumento $390 \%$ las compras de gas a EU."

10. de junio de 1992. "Elevar tarifas de energía eléctrica sugiere el BM a México y CA,"

29 de junio de 1992. "Anuncian un plan carboeléctrico que funcionará en todo el país."

\section{ElFinanciero}

19 de octubre de 1990. "Las ventajas de México en el ALC son petróleo y energéticos: Hanry Mohimann, Dow Chemical".

26 de noviembre de 1990. "México debe incluir energéticos en el ALC, dice Bill Richardson".

4 de diciembre de 1990. "Permitirá el gobierno a particulares participar con más de $30 \%$ en las inversiones del sector eléctrico. Será la manzana de la discordia de empresarios en 1991." 
12 de diciembre de 1990. "Sindicatos y ecologistas de E.U. pueden frenar el ALC con México. No puede ignorarse la importancia de esta gente: Tim Bennet".

8 de enero de 1991. "El congreso estadounidense aprobaría el tratado si se incluye el petróleo, prevé Ciemex-Wharton."

28 de enero de 1991. "Dudan congresistas de EU sobre la firma del ALC con México. La crisis y la recesión estadounidense, las causas: María Teresa Gutiérrez (UNAM)."

29 de enero de 1991. "Abastecerán a EU las plantas generadoras de electricidad situadas en el norte del país. Se exportarán 1,920 gigavatios-hora al año."

15 de mayo de 1991. "Serios retrasos en los programas del sector eléctrico: Posible desabasto de energia en 91."

22 de mayo de 1991. "El sector eléctrico requiere ritmos de desgravación arancelaria menores a los de EU".

28 de mayo de 1991. "Posible, que empresas del sector eléctrico de EU cancelen el contrato de compra-venta con la CFE. Las importaciones, sólo temporales: SDG\&E y SCE."

4 de junio de 1991. "Integración de sistemas de electricidad entre México y EU, propone el Departamento de Energía."

6 de junio de 1991. "Estudian EU y la CFE intercambiar petróleo por electricidad. El compromiso involucrará otras acciones de cooperación,"

26 de junio de 1991a. "Construirán en Tijuana la hidroeléctrica más grande de México."

26 de junio de 1991b. "Planean 6 firmas estadounidenses construir la hidroeléctrica (?) más grande del país en Tijuana. Inversión aproximada, mil millones de dólares."

28 de junio de 1991. "Aumentar representantes obreros en la unidad negociadora del TLC, pide el CT. Reafirma Serra que no se negociarán petróleo, ferrocarriles, telégrafos, electricidad y petroquímica básica."

2 de julio de 1991. "Sospecha el PAN que se pretende privatizar la industria eléctrica: hay 'enredo legal' dice. Se opondría si se manejara como el caso Telmex."

4 de julio de 1991a. "Aumentará el comercio internacional de gas por la apertura de fronteras,"

4 de julio de 1991b. "México, de la autosuficiencia a la importación de hidrocarburos."

12 de agosto de 1991. "Traerá el TLC 'Amplia liberalización' en energía y servicios." 
16 de agosto de 1991. "Construirá empresa estadounidense un gaseoducto Texas-Reynosa."

28 de agosto de 1991. "Intocable la constitución en materia energética, empero habrá contratos para extranjeros: Serra."

6 de septiembre de 1991a. "La privatización de la electricidad al AL, clave para el desarrollo: BM."

6 de septiembre de 1991b. "Para crecer, debe el sector eléctrico buscar fórmulas creativas de financiamiento: Gurría."

18 de septiembre de 1991. "Déficit en la balanza comercial petrolífera y petroquímica."

31 de octubre de 1991. "Gaseras de EU desplazan a Pemex del mercado interno."

8 de noviembre de 1991a. "Destino energético de E.U., en manos de abastecedores foráneos".

8 de noviembre de 1991b. "Urge ajustar el precio de la electricidad en términos reales: SEMIP."

19 de noviembre de 1991. "Los energéticos, de facto en el tratado de libre comercio".

10 de diciembre de 1991. "Propone Canadá la integración trilateral de la industria gasera."

13 de diciembre de 1991. "Desmintió la SEMIP versiones sobre la apertura de gasolinerías extranjeras."

17 de diciembre de 1991a. "Cárdenas: México por acelerar las pláticas ofrece hidrocarburos."

17 de díciembre de 1991b. "Incrementó México los últimos 8 años sus exportaciones de energia eléctrica a EU: CFE."

18 de diciembre de 1991. "Convocará la CFE a la IP para la construcción de 4 plantas eléctricas."

23 de diciembre de 1991. "Necesario, fortalecer la inversión pública en la industria petrolera, advierte Canacintra."

9 de enero de 1992. "Celebran los negociadores reuniones maratónicas para concluir el borrador: fuerte hermetismo."

15 de enero de 1992. "Totalmente abierta al capital foráneo, $73 \%$ de la economía nacional: Sin embargo, aún es selectiva."

21 de enero de 1992a. Reclasificaría México 11 petroquímicos básicos; en petróleo no cederá; en gas, interesado Canadá."

21 de enero de 1992b. "Reservas de gas podrían situar al país en primer plano mundial. México, el 'Gigante Dormido' de la industria gasera norteamericana."

22 de enero de 1992. "Prácticamente descartada, la firma del TLC, si Bush no se reelige: Analistas de Banamex." 
23 de enero de 1992. "Revisarán Serra y Hills, en reunión privada, los avances del TLC."

3 de marzo de 1992, "Crecera 30 por ciento el intercambio comercial con Canadá, pronostican economistas."

6 de abril de 1992. "Con o sin TLC, el sector energético se abrirá a la inversión."

10 de abril de 1992. "El país, capaz de producir gas natural a costos competitivos con los de otros energéticos."

12 de mayo de 1992. "Participará la IP en el autoabastecimiento de energía eléctrica."

26 de mayo de 1992. "Gaseras de EU buscan cortar la producción para elevar precios."

28 de mayo de 1992, "Persiste el deterioro en los términos del intercambio: no se hace nada para detenerlo."

2 de junio de 1992a. "El universo petroquímico, a la IP antes de 1994."

2 de junio de 1992b. "La lucha por el control de la producción de anticontaminantes en México."

4 de junio de 1992. "Seis áreas de la negociación a la agenda de la reunión ministerial: fuertes controversias."

10 de junio de 1992. "Lograr la excelencia empresarial en beneficio nacional, meta de la reestructuración de Pemex."

23 de junio de 1992. "Total integración de México a la industria gasera de EU y Canadá: PMI,"

1 de julio de 1992. "Buscará la CFB financiamiento para producir energía barata y enfrentar retos del TLC."

7 de julio de 1992. "La producción gasera en su nivel más bajo en 12 af̃os." 10 de julio de 1992a. "Esencialmente, lo que a EU le interesa de México es su petróleo, reconoce el ex negociador Grundy."

10 de julio de 1992b. "Libre importación de gasolina y diesel de Estados Unidos a Canađá."

4 de agosto de 1992a. "Con el tratado, México podría incrementar el abasto de petroleo."

4 de agosto de 1992b. "Inaugura la empresa Valero Energy Corporation Gasoducto transfronterizo McAllen-Reynosa."

5 de agosto de 1992. "Captación de capital foráneo, verdadero motivo de México para integrarse con E.U. , dice la OCDE".

6 de agosto de 1992. "Redactan los negociadores el texto de los 18 temas del tratado."

11 de agosto de 1992, "Verdadera arena de boxeo político, la mesa de compras gubernamentales,"

12 de agosto de 1992. "TLC, Pemex y bienes conyugales." 